\title{
Design of centrifugal compressors for heat pump systems
}

\author{
Meroni, Andrea; Zühlsdorf, Benjamin; Elmegaard, Brian; Haglind, Fredrik
}

\section{Published in:}

Applied Energy

Link to article, DOI:

10.1016/j.apenergy.2018.09.210

Publication date:

2018

Document Version

Peer reviewed version

Link back to DTU Orbit

Citation $(A P A)$ :

Meroni, A., Zühlsdorf, B., Elmegaard, B., \& Haglind, F. (2018). Design of centrifugal compressors for heat pump systems. Applied Energy, 232, 139-156. https://doi.org/10.1016/j.apenergy.2018.09.210

\section{General rights}

Copyright and moral rights for the publications made accessible in the public portal are retained by the authors and/or other copyright owners and it is a condition of accessing publications that users recognise and abide by the legal requirements associated with these rights.

- Users may download and print one copy of any publication from the public portal for the purpose of private study or research.

- You may not further distribute the material or use it for any profit-making activity or commercial gain

- You may freely distribute the URL identifying the publication in the public portal

If you believe that this document breaches copyright please contact us providing details, and we will remove access to the work immediately and investigate your claim. 


\title{
Design of centrifugal compressors for heat pump systems
}

\author{
Andrea Meroni $^{\mathrm{a}, *}$, Benjamin Zühlsdorf ${ }^{\mathrm{a}}$, Brian Elmegaard ${ }^{\mathrm{a}}$, Fredrik Haglind ${ }^{\mathrm{a}}$ \\ ${ }^{a}$ Department of Mechanical Engineering, Technical University of Denmark, Nils Koppels Allé, Building 403, 2800 Kongens Lyngby, Denmark
}

\begin{abstract}
This work presents a mean-line model of a centrifugal compressor and a method for a coupled optimization with a heat pump system. The compressor model was validated with five test cases from the open literature including the working fluids: air, refrigerant R-134a and carbon dioxide. Afterwards, the compressor model was coupled and optimized with that of a heat pump cycle supplying steam at $150{ }^{\circ} \mathrm{C}$. Two cycle configurations were considered: an open-loop system using steam, and a closed-loop system with five other working fluid candidates. The compressor was designed using a multi-objective optimization algorithm, which seeks to maximize simultaneously the cycle coefficient of performance and the supplied heat flow rate. The method employed in this work considers the possible trade-offs regarding cycle and compressor design criteria, and can be used to identify cost-effective solutions for the next generation of heat pumps. The obtained results suggest that a two-stage compressor using steam yields the highest values of coefficient of performance and heat supply, and at the same time requires a more challenging compressor design.
\end{abstract}

Keywords: turbocompressor, validation, preliminary design, refrigerant, high-temperature heat pump 2010 MSC: 00-01, 99-00

\section{Introduction}

Heat pump systems are regarded as a viable and attractive solution to recover excess heat from low-tomedium temperature heat sources of many industrial processes [1-3].

Chua et al. [4] and Arpagaus et al. [2] reviewed the most important advances in the field. The application of heat pump systems is currently extending to the generation of high-temperature heat (with heat sink temperatures above approximately $100^{\circ} \mathrm{C}$ ). The International Energy Agency (IEA) [5] produced a report on industrial heat pumps, indicating the markets, level of technological maturity, applications and barriers of heat pumps. The report highlights that the theoretical potential for application of industrial heat pumps increases significantly for heat sink temperatures up to and higher than $100{ }^{\circ} \mathrm{C}$. Nellisen and Wolf [6] investigated the heat demand across different industries in the European market and indicated that about $626 \mathrm{PJ}$ (174 TWh) of heat is reachable by industrial heat pumps, of which about $113 \mathrm{PJ}(19 \%)$ is in the temperature range $100{ }^{\circ} \mathrm{C}$

\footnotetext{
${ }^{*}$ Corresponding author

Email addresses: andmer@mek.dtu.dk (Andrea Meroni), bezuhls@mek.dtu.dk (Benjamin Zühlsdorf), be@mek.dtu.dk (Brian Elmegaard), frh@mek.dtu.dk (Fredrik Haglind)
}

to $150^{\circ} \mathrm{C}$. Recently, Arpagaus et al. [3] presented a comprehensive review on high-temperature heat pump (HTHP) systems, concluding that industrial HTHPs can potentially supply the industrial European demand of 113 PJ.However, the literature highlights that the development of mass-produced units is hindered by many factors, such as low awareness of the heat consumption in companies and the possible technical solutions [3, 5]; lack of knowledge of comprehensive heat pump integration methods $[3,5,7]$; lack of available refrigerants with low global warming potential in the high-temperature range [3, 8]; lack of cost-efficient solutions and long payback periods $[5,8,9]$; and the technical challenges related to the compressor operation at high temperatures [10].

In this respect, the centrifugal compressor (CC) technology is seen as an attractive option compared with positive displacement compressors, since it bears key advantages such as the potential for high efficiency, the possibility to operate at high pressure ratios, a compact design, and oil-free operation [11, 12]. The progress of the technology in the last decades, and, foremost, the introduction of high-speed generators, have made it possible to apply CCs even to smaller units in the refrigeration and heat pump fields. Hastbacka et al. [13] claimed that small centrifugal compressors are expected to re- 
place reciprocating and screw compressors for chilledwater systems in the range $88 \mathrm{~kW}$ to $281 \mathrm{~kW}$ as their high initial cost is offset by improved energy efficiency. Süß [14] developed a centrifugal compressor for refrigeration applications with a nominal power of $7 \mathrm{~kW}$, operating up to $90 \mathrm{krpm}$ and achieving an overall efficiency of $70 \%$ (including the motor). Bertsch et al. [15] conducted a study on the use of micro turbocompressors in HTHPs, concluding that such compressors are a viable alternative to traditional technology. The working fluid can range from natural to synthetic refrigerants, and the compressor can experience considerably different flow phenomena according to the selected medium. The combination of high rotational speed, the variety of possible working fluids, and the compact size often result in highly loaded compressors whose design requires the adoption of suitable numerical tools and modeling strategies.

The first step in the design of a centrifugal compressor is performed using one-dimensional preliminary design models. One-dimensional numerical methods, also called mean-line models, provide the design and performance estimation of the centrifugal compressor through the solution of the governing equations at the mean streamline and at the main stations of the compressor components. Compared to more advanced methods, i.e. through-flow or computational fluid dynamics (CFD), mean-line models provide the design and performance estimation of the machine in a relatively short time and with low computational effort. Harley et al. [19] investigated different $1 \mathrm{D}$ methods for the performance prediction of CCs and concluded that the 1D single-zone method is the most suitable for the preliminary design process, since it provides the opportunity to analyze and reduce the internal losses even for modern designs.

At the same time, the validity of preliminary design models for CCs needs to be assessed to ensure that the accuracy and reliability criteria required in the design process are met. Table 1 lists the mean-line models that were developed for CCs and their corresponding validation methods.

All the models in Table 1 were developed and validated using test cases for a single working fluid. In particular, only three mean-line models published in the open literature employed a working fluid which is used in heat pumps, and these are the models by Schiffmann and Favrat [11], Vilim [21] and Kus and Nekså [18]. The robustness of a numerical model in its prediction capability relies not only on its accuracy for different geometries, but also on its suitability when using different working fluids. This is especially relevant for heat pump systems where, in the early design process, differ- ent working fluids can be employed, and the machine geometry and performance need to be carefully evaluated for each working fluid candidate. However, the existing literature lacks investigations on the suitability of mean-line models for the design and performance prediction of centrifugal compressors considering different working fluids. In particular, the existing loss correlations were derived from a pool of compressor data operating with air, casting doubt on the suitability when different working fluids are used.

Moreover, a widely adopted approach in the design of HP cycles is to decouple the design of the thermodynamic cycle from that of the compressor. In this case, the heat pump is typically designed by assigning a guess value in the isentropic efficiency and volume flow rate of the compressor. This approach was used in previous studies [32-37] for the design of different heat pumps and to select the most suitable working fluid. However, decoupling the design of the thermodynamic cycle from that of the compressor, may lead to inaccurate estimations of the cycle performance and complex or unfeasible compressor design solutions. Moreover, the working fluid represents an additional degree of freedom in the design process, and can greatly affect both the system and the compressor designs. In this respect, a combined design of the thermodynamic cycle and the compressor is particularly important to ensure that the working fluid selection includes considerations of the performance and the technical aspects of both the cycle and compressor.

Combined design optimization of the system and a turbomachine was recently adopted for the design of organic Rankine cycle power systems. For example, Da Lio et al. [38] proposed the design optimization of organic Rankine cycle systems using performance maps of single-stage axial turbines generated with a meanline model and integrated into the system design model. White and Saima [39] proposed a similar approach, in which the performance maps were developed for radialinflow turbines and were used to design the organic Rankine cycle power system. Meroni et al. [40, 41] and La Seta et al. [42] presented a method for the optimization of an organic Rankine cycle system with single and multi-stage axial turbines. In the field of heat pump applications, there are few works related to the simultaneous preliminary design optimization of CCs and the thermodynamic cycle. Shiffmann and Favrat [11] developed a mean-line model for CCs and optimized the compressor for different heat pump operating points to minimize the overall seasonal energy consumption and to maximize the overall seasonal compressor isentropic efficiency. Schiffmann [12] proposed designing 
Table 1: Review of mean-line models developed for centrifugal compressors in the open literature.

\begin{tabular}{llll}
\hline Author & Ref. & Year & Model validation \\
\hline Li et al. & {$[16]$} & 2015 & Off-Design, air compressor with vaneless and vaned diffusers \\
Klausner and Gampe & {$[17]$} & 2014 & 1-D, Off-Design, six air compressors \\
Kus and Nekså & {$[18]$} & 2013 & Design point, CO Compressor $^{2}$ compros compressors \\
Harley et al. & {$[19]$} & 2012 & 1-D, Off-Design, three turbocharger \\
Casey & {$[20]$} & 2012 & 0-D, Off-Design, turbocharger compressor \\
Vilim & {$[21]$} & 2010 & Design point, CO 2 compressor \\
Schiffmann and Favrat & {$[11]$} & 2009 & Off-design maps, R134a compressor \\
Veres & {$[22]$} & 2009 & Off-design maps, three axial single and multi-stage compressors \\
Oh et al. & {$[23]$} & 1997 & Off-design maps, four air compressors \\
Aungier & {$[24]$} & 1995 & Off-design map, five air compressors with vaned and vaneless diffusers \\
Perdichizzi and Savini & {$[25]$} & 1985 & Off-design map, air compressor with vaned diffuser, off-design \\
Galvas & {$[26]$} & 1973 & Off-design map, air compressor with vaned diffuser, off-design \\
Rodgers & {$[27-30]$} & $1964-1984$ & Off-design map, thirteen backswept air impellers with vaned diffuser \\
Coppage & {$[31]$} & 1956 & Aeroderivative air compressor, subsonic and supersonic conditions, off- \\
& & & design maps \\
\hline
\end{tabular}
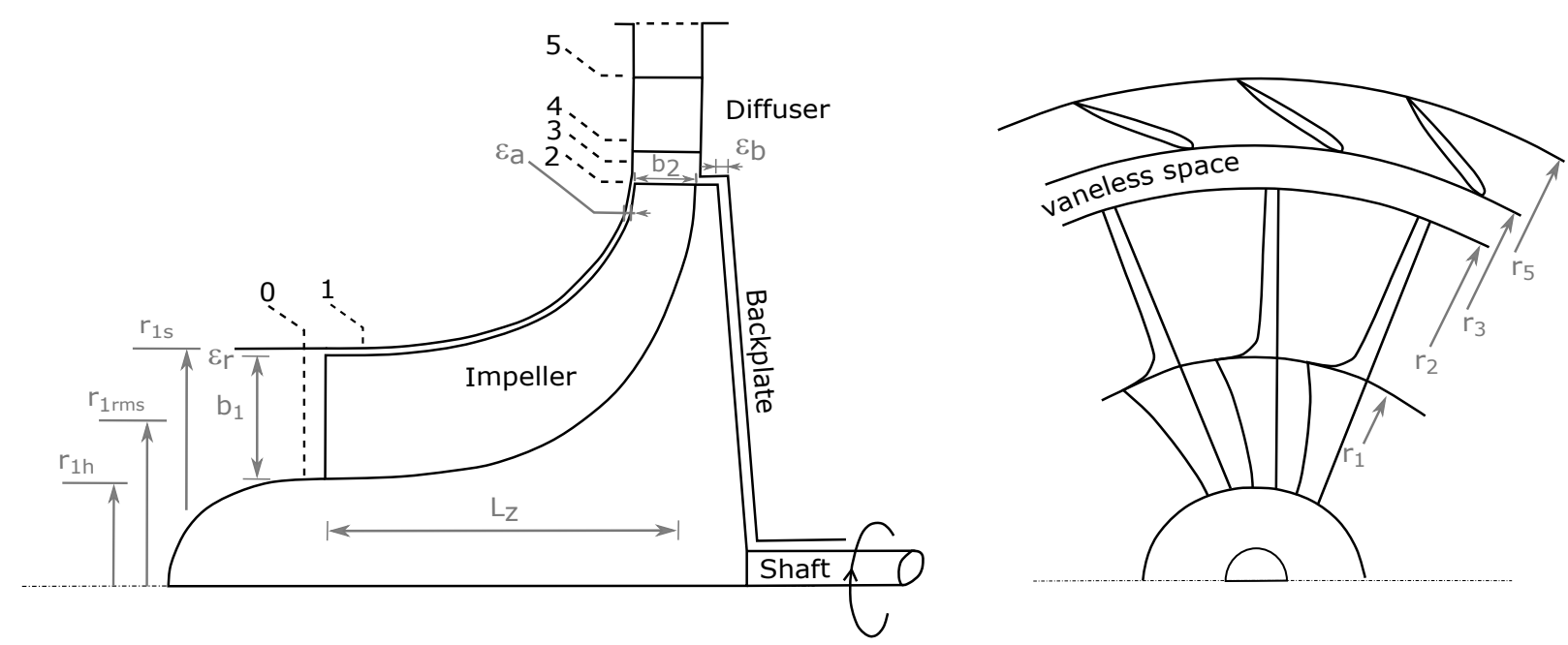

Figure 1: Schematic of the centrifugal compressor geometry.

the centrifugal compressor by integrating the different models of the compressor components. The proposed approach showed an increase of the seasonal compressor efficiency of more than $12 \%$-points compared to the traditional design methods. Javed et al. [43] proposed a method to design turbocompressors and heat pump systems by including different levels of design complexity, from the preliminary design with a mean-line model to the more advanced 3D impeller aerodynamic design.

None of the aforementioned works, Refs. [11, 12, 43], performed the design of the turbocompressor and the heat pump system including also the selection of the most suitable working fluid, which is an important key decision variable in the system design. Instead, the fluid was selected a priori in the design process. Moreover, only Ref. [43] interfaced a heat pump simulation model with that of a centrifugal compressor. In this case, the optimization method involved the use of both mean-line and CFD tools, requiring considerable time and computational efforts which might not be suitable for the screening of design solutions using different working fluids at the very early stage of the design process.

The objective of this paper is to develop a method for the combined design of high-temperature heat pumps and centrifugal compressors including the selection of the most suitable working fluid. To this end, a steadystate mean-line model of a centrifugal compressor was developed for the design and off-design performance prediction of CCs. The model formulation solves the governing equations with state-of-the-art equations of state for the estimation of the fluid thermodynamic and transport properties. Also, the method adopted in this 
work accounts for the onset of choking conditions in the compressor. In order to assess the suitability of the model using different working fluids, some validation test cases were performed including three working fluids: air, a synthetic refrigerant (R134a), and $\mathrm{CO}_{2}$. The latter two test cases were the only ones in the open literature presenting well-documented data of CCs employing a fluid different from air. The compressor model was then coupled to that of a HTHP, and the combined model was optimized.

The primary novel contributions of this paper are the following: (1) assessment of the suitability of a meanline centrifugal compressor model and its loss correlations to different geometries and working fluids (air, $\mathrm{R} 134 \mathrm{a}$ and $\mathrm{CO}_{2}$ ); and (2) a method for the combined optimization of a heat pump equipped with centrifugal compressors enabling the selection of the most suitable working fluid in the early stage of the design process.

The results and methods may be used to support engineers and researchers in identifying cost-effective solutions in terms of design and working fluid selection for the next generation of heat pumps.

The work is structured as follows: in Section 2 the design and off-design models of the compressor, the test cases and methods used for validation, and the optimization method are presented. In Section 3 the results of the compressor model validation and the optimization method are discussed. In Section 4 the results are presented, and in Section 5 the conclusions are drawn.

\section{Methods}

This work employed a steady-state, mean-line model for the performance prediction of CCs at the design and off-design conditions. The model was written in the MATLAB language [44] and followed a mean-line approach, based on which the thermodynamic and flow conditions were computed at the mean streamline in the turbine meridional plane, and were representative of mass-weighted averaged conditions over the whole section. The development of the model focused on the modeling of the compressor impeller, and the vaneless and vaned diffusers. Figure 1 depicts a schematic of the centrifugal compressor highlighting the main stations, the terminology and the symbols used in this paper. The thermodynamic and flow conditions in the main modeling stations were computed by the simultaneous solution of mass continuity, energy balance, and loss equations. The fluid properties were computed using realgas equations of state using the thermodynamic libraries CoolProp [45] and REFPROP [46].
A key aspect in the development of the mean-line model was the identification of the choking point inside the compressor stage. Choking occurs when the local velocity of the fluid inside the compressor passages reaches the speed of sound [47]. In a compressor, choking usually occurs in the blade passages of the impeller or in the vaned diffuser at the point of minimum flow area [48]. The onset of choking is also influenced by the rotational speed of the impeller, since this will determine the value of the local relative velocity in the rotating coordinate system. When the compressor chokes, the mass flow rate cannot further increase and the performance drops abruptly, compromising the effective operational range of the machine. For any given operating condition, the method described here aims to identify the choking point by evaluating the possibility of choking conditions in the impeller inlet, the impeller outlet, or in the vaned diffuser.

\subsection{Design model}

Figure 2(a) shows the workflow of the preliminary design model. The inputs to the compressor model are the inlet total temperature $T_{01}$, the inlet total pressure $p_{01}$, the rotational speed $\mathrm{N}$, the mass flow rate $\dot{m}$, and the stage total-to-static pressure ratio $\mathrm{PR}_{\mathrm{ts}}$. In addition, a set of decision variables related to the compressor geometry and fluid dynamic conditions needs to be given as an input. Table 2 shows the design variables and the optimization constraints used in this work. The upper and lower boundaries are imposed to find solutions which are manufacturable, physically meaningful and technically feasible. An upper bound in the tip speed is also imposed to limit the mechanical stresses on the blades. The optimization constraints were selected from the open literature according to Refs. [11, 25]. The modeling strategy of Figure 2(a) applies to a predefined set of decision variables, and a dedicated optimization procedure needs to be applied to determine the set of decision variables producing an optimal compressor design, see Sec. 2.5. Not all the design variables need to be specified in the design code, and some of them may be fixed by the requirements of the specific application. The number of impeller blades, with or without splitters, can be included in the design and off-design modeling strategy either as an additional decision or input variable. In the design model the number of blades was calculated as a function of the total-to-total stage pressure ratio using an empirical correlation derived from a pool of compressor data of Ref. [49]:

$$
\begin{aligned}
& Z_{\mathrm{r}}=12.03+2.544 \mathrm{PR}_{\mathrm{tt}} \quad \text { (without splitters) } \\
& Z_{\mathrm{r}}=-4.527 e^{1.865 / \mathrm{PR}_{\mathrm{tt}}}+32.22 \quad \text { (with splitters) }
\end{aligned}
$$




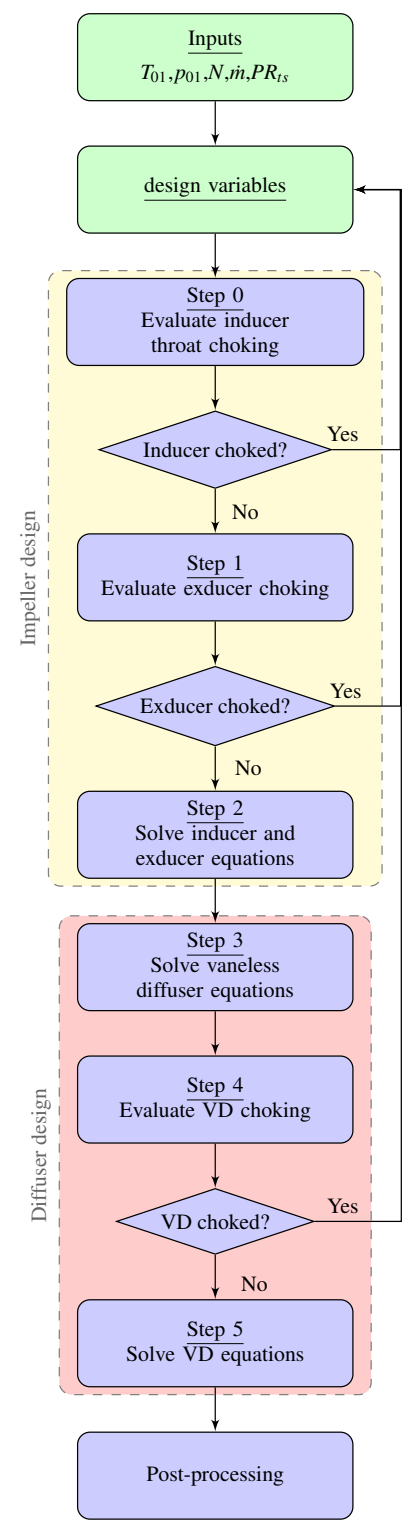

(a)

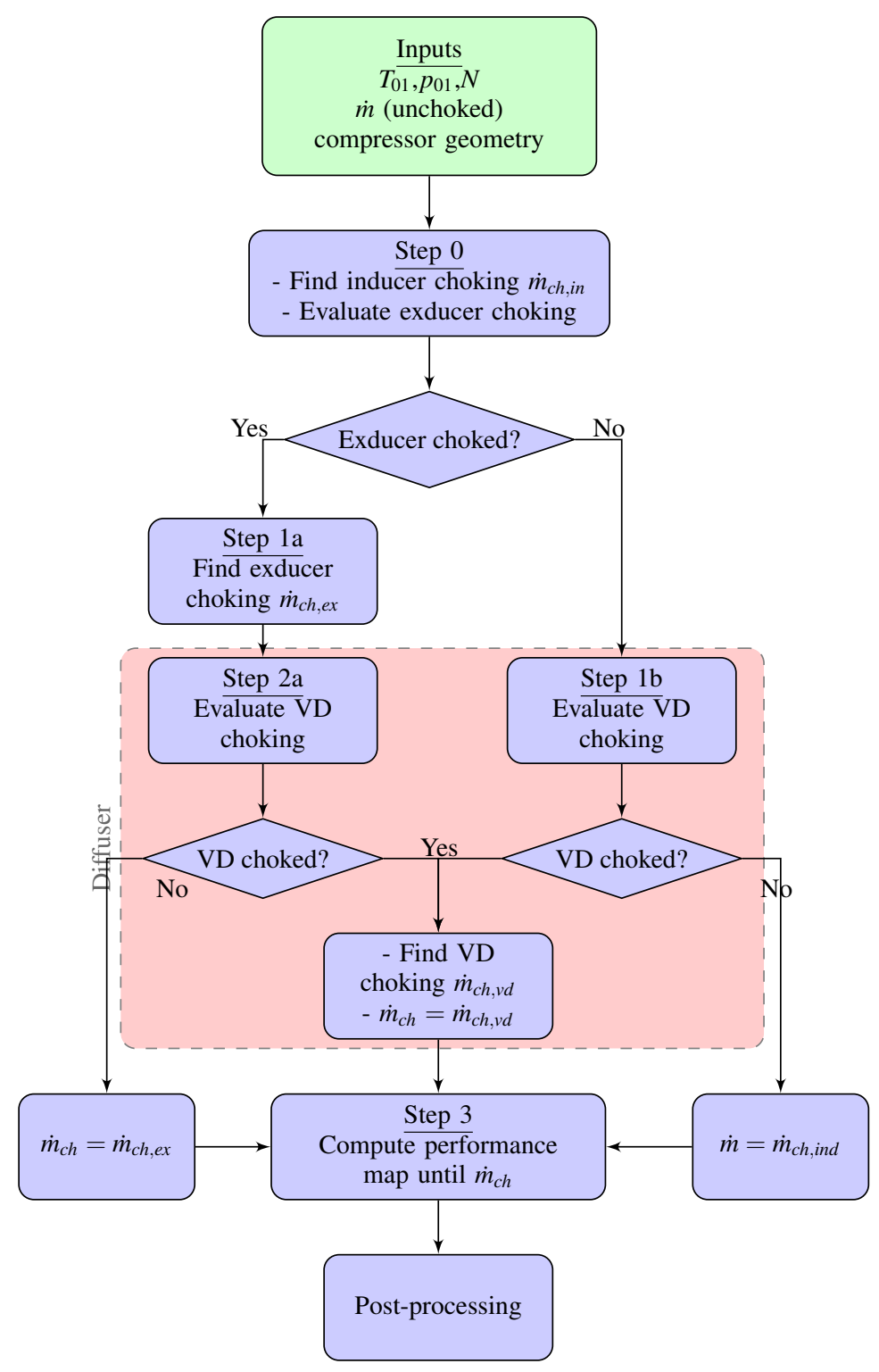

(b)

Figure 2: Modeling strategy for centrifugal compressors: (a) preliminary design model; (b) analysis model.

where $Z_{r}$ is the number of impeller blades, rounded to the closest integer value, and $\mathrm{PR}_{\mathrm{tt}}$ the stage total-to-total pressure ratio. Equations 1 and 2 are valid for values of a design pressure ratio in the range 1.0 to 5.0 and 1.8 to 8.0 , respectively.

The implementation of the design model follows the approaches by Japikse and Baines [50] and Whitfield and Baines [51].

For a given set of input and decision variables, the first step in the design modeling strategy is to identify whether the compressor stage is choked (Step 0). If the compressor stage is choked, the decision variables need to be changed to allow for a higher mass flow rate through the machine. Mass and energy balances, and the isentropic process formulation in the inducer throat 
Table 2: Design variables and optimization constraints of the compressor design model.

\begin{tabular}{|c|c|c|c|c|}
\hline Decision variable & Description & Units & $\begin{array}{c}\text { Lower } \\
\text { boundary }\end{array}$ & $\begin{array}{c}\text { Upper } \\
\text { boundary }\end{array}$ \\
\hline$\psi_{\text {is }}=\Delta h_{0, \text { is }} / U_{2}^{2}$ & Isentropic stage loading coefficient & {$[-]$} & 0.3 & 1.1 \\
\hline$N$ & Rotational speed & {$[\mathrm{krpm}]$} & 1 & 210 \\
\hline$r_{1 \mathrm{~s}} / r_{2}$ & Inlet shroud to tip radius ratio & {$[-]$} & 0.4 & 0.7 \\
\hline$r_{1 \mathrm{~h}} / r_{1 \mathrm{~s}}$ & Inlet hub to shroud radius ratio & {$[-]$} & 0.25 & 0.7 \\
\hline$b_{2} / r_{2}$ & Exit blade width over radius & {$[-]$} & 0.02 & 0.8 \\
\hline$\beta_{2 b}$ & Impeller exit blade angle & {$\left[{ }^{\circ}\right]$} & -45 & 0 \\
\hline$\beta_{1 \mathrm{~b}}$ & Impeller inlet average blade angle & {$\left[{ }^{\circ}\right]$} & -70 & -20 \\
\hline \multicolumn{5}{|c|}{ Optional decision variables } \\
\hline$Z_{\mathrm{r}}$ & Number of total impeller blades & {$[-]$} & 6 & 60 \\
\hline \multicolumn{5}{|c|}{ Additional constraints } \\
\hline$M_{1 \mathrm{~s}, \mathrm{rel}}$ & Relative Mach number at impeller inlet shroud & {$[-]$} & 0 & 1.4 \\
\hline$M_{1, \text { rel }}$ & Relative Mach number at impeller inlet & {$[-]$} & 0 & 0.9 \\
\hline$W_{2} / W_{1 \mathrm{~s}}$ & Ratio of exit to inlet shroud relative velocities & {$[-]$} & 0.25 & - \\
\hline$\alpha_{2}$ & Impeller exit absolute flow angle & {$\left[{ }^{\circ}\right]$} & - & 85 \\
\hline$o_{1}$ & Impeller inlet throat & {$[\mathrm{mm}]$} & 1.49 & 50 \\
\hline DR & Stage degree of reaction & {$[-]$} & -0.1 & 0.9 \\
\hline$U_{2}$ & Impeller exit peripheral speed & {$[\mathrm{m} / \mathrm{s}]$} & 0 & 400 \\
\hline$r_{3} / r_{2}$ & Vaneless diffuser radius ratio & {$[-]$} & 1.05 & 2 \\
\hline \multicolumn{5}{|c|}{ Fixed values (if not specified) } \\
\hline$t_{\mathrm{b}}$ & Blade thickness & {$[\mathrm{mm}]$} & 0.2 & \\
\hline$\varepsilon$ & Impeller clearance & {$[\mathrm{mm}]$} & 0.15 & \\
\hline$\varepsilon_{\mathrm{b}}$ & Impeller back face clearance & {$[\mathrm{mm}]$} & 1 & \\
\hline$k_{\mathrm{s}}$ & Impeller surface roughness & {$[\mathrm{mm}]$} & 0.002 & \\
\hline$b_{3} / b_{2}$ & Diffuser width ratio & {$[-]$} & 1 & \\
\hline $\mathrm{CP}$ & Diffuser pressure coefficient & {$[-]$} & 0.44 & \\
\hline
\end{tabular}

section are expressed as

$$
\begin{aligned}
& W_{1}=\dot{m} /\left(\rho_{1} A_{\mathrm{th}, 1}\right) \\
& h_{1}=h_{01}-\frac{1}{2} W_{1}^{2}+\frac{1}{2} U_{1, \mathrm{rms}}^{2} \\
& s_{01}-s_{1}=0
\end{aligned}
$$

where $\rho_{1}, A_{\mathrm{th}, 1}, W_{1}, U_{1, \mathrm{rms}}$, and $h_{1}$ are the density, crosssectional flow area, relative velocity, root-mean-square average peripheral speed, and static specific enthalpy at the inducer throat section, respectively. The term $h_{01}$ denotes the total specific enthalpy, and $s_{01}$ and $s_{1}$ are the total and static specific entropies, respectively. Equation 5 assumes an isentropic process from the inducer inlet to the throat. For given inducer inlet conditions and geometry, the solution strategy adopted above allows expressing $s_{01}-s_{1}$ as a residual function of $\rho_{1}$ and $\dot{m}$, as illustrated in Figure 3. For a given value of mass flow rate, the residual function shows a non-monotonic behavior with a maximum. The condition at which the peak of this function crosses the abscissa was identified as the choking condition. For small values of $\dot{m}$, when the maximum is above the density axis, there are two values of $\rho_{1}$ which satisfy Eq. 5. The larger value represents subsonic flow conditions, whereas the smaller value corresponds to supersonic flow conditions. By increasing the mass flow rate, the peak of the curve moves

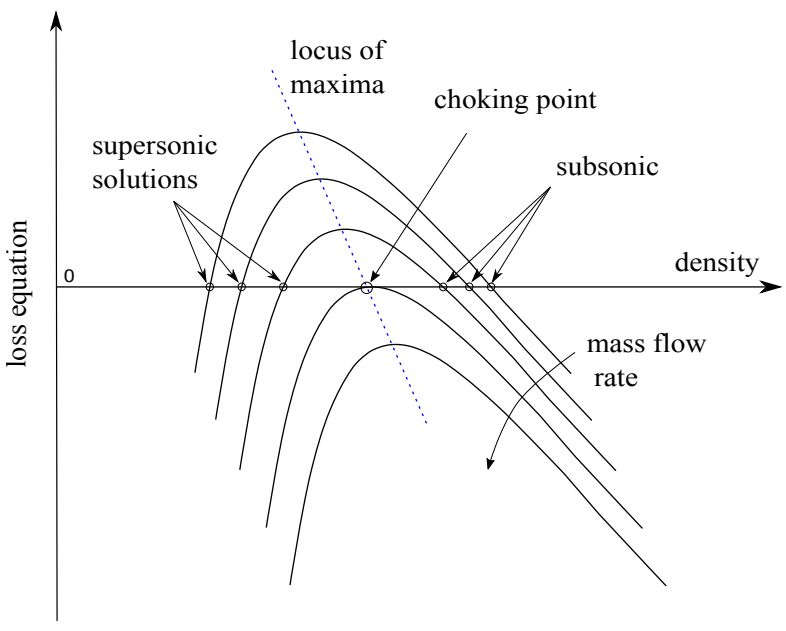

Figure 3: Identification of the choking point for a blade row.

downwards, and eventually crosses the abscissa. Accordingly, choking occurs when the subsonic and supersonic solutions coincide, and the Mach number at the throat is unity. Figure 3 shows that there is no solution to the system of equations for values of mass flow rate higher than that of the choking condition. In this 
case, the design process ends and a different set of design variables needs to be provided to comply with the required input conditions. If choking does not occur, the modeling strategy proceeds by evaluating whether choking may be present at the exducer section (step 1).

To this end, the equations for mass continuity, momentum and the losses at the exducer section 2 are expressed as

$$
\begin{aligned}
& C_{2 m}=\dot{m} /\left(\rho_{2} A_{2}\right) \\
& h_{02}=h_{01}+C_{2 \mathrm{t}} U_{2}-C_{1 t} U_{1, \mathrm{rms}} \\
& \sum_{n=1}^{n_{\text {loss }}} \Delta h_{\text {loss,imp }}-h_{02}+h\left(p_{02}, s_{01}\right)=0
\end{aligned}
$$

where $\Delta h_{\text {loss,imp }}$ is one of the $n$ impeller losses, which is modeled using the empirical correlations presented in Sec. 2.3. To solve Eq. 7, an expression for the tangential component of the rotor exit absolute velocity, $C_{2 t}$, was derived using the component in the meridional direction, $C_{2 m}$, and the slip factor $\sigma$, which provides a measure of the flow deviation at the impeller exit. Based on the slip factor, a slip velocity can be computed, and the absolute and tangential velocities at the impeller exit are the following:

$$
\begin{aligned}
& C_{2 t}=\sigma U_{2}-C_{2 m} \tan \left(\left|\beta_{2 \mathrm{~b}}\right|\right) \\
& C_{2}=\sqrt{C_{2 m}^{2}+C_{2 t}^{2}} \\
& h_{2}=h_{02}-\frac{1}{2} C_{2}^{2}
\end{aligned}
$$

The left side of Eq. 8 can be plotted as a function of the mass flow rate and the impeller exit density, obtaining a trend similar to that of Figure 3. Subsequently, the impeller exit is evaluated for whether or not it is choked, which results in a termination of the design process. If the impeller is not choked, Eqs. 6-8 are solved to determine the thermodynamic and flow conditions at the impeller exit section (Step 2). If the stage has only the impeller, the design process ends, and the model performs the post-processing operations necessary to compute the performance and the final design of the machine.

In the presence of a vaneless diffuser, the total pressure loss coefficient $K$ and the ideal pressure coefficients were computed based on the specified stage exit total pressure $p_{03}$ and pressure coefficient $\mathrm{CP}$ as follows:

$$
\begin{aligned}
& K=\frac{p_{02}-p_{06}}{p_{02}-p_{2}} \\
& p_{3}=p_{2}+\mathrm{CP}\left(p_{02}-p_{2}\right) \\
& \mathrm{CP}_{\text {id }}=\mathrm{CP}+K
\end{aligned}
$$

The vaneless diffuser exit state was then determined by solving the following set of equations for the exit den- sity $\rho_{3}[50]$ :

$$
\begin{aligned}
& h_{3}=h\left(\rho_{3}, p_{3}\right) \\
& C_{3}=\sqrt{2\left(h_{02}-h_{3}\right)} \\
& \dot{m}-C_{3} \rho_{3} A_{2} \cos \left(\alpha_{2}\right)\left(1-\mathrm{CP}_{\mathrm{id}}\right)^{-0.5}=0
\end{aligned}
$$

A feature of the vaneless diffuser is that it has no throat section and, therefore, it cannot be choked [48]. If a vaned diffuser (VD) is present (Step 4), the model needs to evaluate whether choking may occur in its throat section according to the method followed so far. The vaned diffuser throat equations are expressed as

$$
\begin{aligned}
& C_{4}=\dot{m} /\left(\rho_{4} A_{\mathrm{th}, 4}\right) \\
& h_{4}=h_{03}-\frac{1}{2} C_{4}^{2} \\
& s_{03}-s_{4}=0
\end{aligned}
$$

If the vaned diffuser is not choked, the governing equations are solved as follows (Step 5):

$$
\begin{aligned}
& C_{5}=\dot{m} /\left(\rho_{5} \cos \alpha_{5} A_{5}\right) \\
& h_{5}=h_{03}-\frac{1}{2} C_{5}^{2} \\
& \sum_{n=1}^{n_{\text {loss }}} \Delta h_{\text {loss }, \mathrm{vd}}-h_{03}+h\left(p_{5}, s_{3}\right)=0
\end{aligned}
$$

In the design mode, the pressure at the exit, $\mathrm{p}_{5}$, was specified by the required stage pressure ratio, and the flow angle $\alpha_{5}$ was determined to match $\mathrm{p}_{5}$. In the offdesign mode, the vaned diffuser exit pressure was unknown. In this case, the exit flow angle was approximated with the vane exit angle assuming a negligible exit flow deviation [50]. Equation 20 was expressed as a function of the impeller exit density $\rho_{5}$, showing a trend similar to that in Figure 3. Similarly to the impeller modeling, if the VD was already choked, the design routine ended. Alternatively, the VD equations were solved, and the compressor design was completed by the post-processing of the data.

\subsection{Off-design model}

Figure 2(b) shows the off-design modeling strategy. In this case an existing compressor design, or one calculated as in Fig. 2(a), was provided as the input and compressor performance maps were generated as the output. The model inputs were the same as the design model, except that the full turbine geometry is given as well. The mass flow rate $\dot{m}$ was provided as an input for the generation of the performance maps. The workflow of Figure 2(b) applies to a single speed line, and an iterative process was implemented to generate the performance map for different values of the compressor rotational speed. 


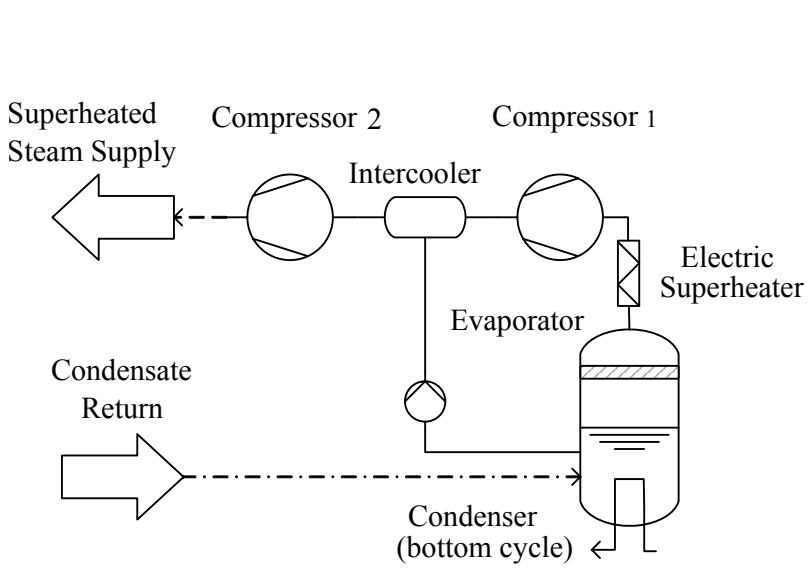

(a)

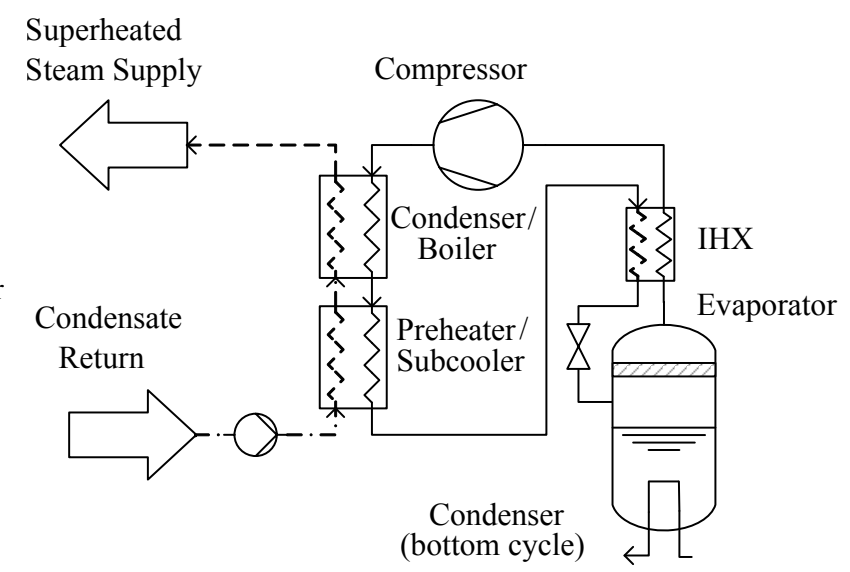

(b)

Figure 4: Layout of the HP cycle for steam generation using: (a) an open-loop with steam and (b) a closed-loop with other working fluids.

The off-design modeling strategy started by evaluating whether, for the given input conditions, the inducer or the exducer was the first to choke (Step 0). The set of Eqs. 3-5 were used for the inducer throat. In step 0 , the inducer choking mass flow rate is found by determining the zero of the locus of maxima of the left side function in Eq. 5. Afterwards, the algorithm evaluates whether the exducer is already choked for the inducer choking mass flow rate by identifying the location of the peak of the residual loss function in Eq. 8. Like in the design strategy, the off-design method evaluates whether the exducer choking mass flow rate is smaller than the inducer choking mass flow rate, and follows two different paths according to the result. If the exducer chokes first, the exducer choking mass flow rate is found by solving Eqs. 3-5 and finding the zero of the locus of maxima in Eq. 8. After determining the choking mass flow rate, performance maps are computed by changing the mass flow rate until obtaining the choking value (step 3).

A one-dimensional model has been implemented to solve the governing equations from the inlet to the outlet of the radial vaneless space (Step 3). Stanitz [52] presented a set of one-dimensional equations for the adiabatic flow in a vaneless radial diffuser including the effect of friction. The equations for radial and tangential momentum, mass continuity and energy balance can be derived from a fundamental control volume analysis applied to the vaneless diffuser or by rearranging and simplifying the Navier-Stokes equations [50, 51]. They are formulated as

$$
\begin{aligned}
& C_{m} \frac{d C_{m}}{d r}-\frac{C_{t}^{2}}{r}+C_{f} \frac{C^{2} \cos (\alpha)}{b}+\frac{1}{\rho} \frac{d p}{d r}=0 \\
& C_{m} \frac{d C_{t}}{d r}+\frac{C_{m} C_{t}}{r}+C_{f} \frac{C^{2} \sin (\alpha)}{b}=0 \\
& \frac{1}{\rho} \frac{d \rho}{d r}+\frac{1}{C_{m}} \frac{d C_{m}}{d r}+\frac{1}{b} \frac{d b}{d r}+\frac{1}{r}=0 \\
& h_{02}-h-\frac{1}{2} C^{2}=0
\end{aligned}
$$

where $b$ is the vaneless space width, provided at every point by linear interpolation between the inlet and outlet values, and $C_{f}$ is the friction factor which was estimated using the correlation proposed by Japikse [53] $C_{f}=\mathrm{k}\left(1.8 \cdot 10^{5} / R e\right)^{0.2}$. The parameter k is an empirical constant which equals values between 0.005 and 0.02 . In this work, the best match with the experimental data was found for the value 0.0050 . The system of equations 24-27 was solved using MATLAB ODE15i solver [44] using the initial values of $C_{m}, C_{t}, \rho$ and $p$ at the impeller exit.

In the presence of a vaned diffuser, which may choke before the impeller, Steps $2 a$ and $l b$ were added, evaluating whether the diffuser was choked. In that case, the choking mass flow rate was determined by solving for the zero of the locus of maxima in the set of Eqs. 21-23.

The volute, placed after the diffuser, was also included in the off-design modeling. The flow in the volute is treated as incompressible following the indications by Japikse and Baines [50]. Mass and energy balances, and the equations for losses accounting for the entropy generation between the volute inlet and outlet, 
are solved as follows:

$$
\begin{aligned}
& \rho_{4}=\rho_{3} \\
& C_{4}=\dot{m} /\left(\rho_{4} A_{4}\right) \\
& h_{4}=h_{03}-\frac{1}{2} C_{4}^{2} \\
& h_{04}-h_{04, \mathrm{~s}}=k_{\mathrm{v}} C_{3}^{2}
\end{aligned}
$$

where $\mathrm{k}_{\mathrm{v}}$ is an empirical coefficient set to 0.5 .

\subsection{Empirical models for losses and flow deviation}

Several empirical correlations for losses and flow deviation in a centrifugal compressor exist, see Refs. $[23,48,51,54,55]$. Table 4 shows a summary of the set of loss models used in this work. These correlations were selected as they were well described in the original references and provided the best match with the data of the test cases.

To close the set of equations 6-8, employed to solve the impeller exit state, an expression for the slip factor has to be provided. This work used the model by Wiesner [56] for the estimation of the slip factor. This model was further improved by Aungier who introduced a limit for high impeller radius ratios, accounting also for splitter blades as follows:

$$
\sigma=1-\frac{\sqrt{\cos \beta_{2 b}}}{Z_{\mathrm{r}}^{0.7}}
$$

Equation 32 is valid up to the limiting radius ratio given by

$$
\begin{aligned}
& \left(r_{1} / r_{2}\right)_{\lim }=\frac{\sigma-\sigma^{*}}{1-\sigma^{*}} \\
& \sigma^{*}=\sin \left(19^{\circ}+0.2\left(90-\left|\beta_{2 b}\right|\right)\right)
\end{aligned}
$$

When the actual impeller radius ratio $r_{1} / r_{2}$ exceeds the limiting value $\left(r_{1} / r_{2}\right)_{\text {lim }}$, a corrected slip factor is computed as follows:

$$
\sigma_{\text {cor }}=\sigma\left[1-\left({\frac{\left(r_{1} / r_{2}\right)-\left(r_{1} / r_{2}\right)_{\lim }}{1-\sigma_{\lim }}}^{\sqrt{\left(90-\beta_{2 b}\right) / 10}}\right)\right]
$$

\subsection{Validation}

The CC model was validated against five welldocumented test cases available in the open literature. Moreover, the test cases encompass a range of different applications and employ three different working fluids: air, $\mathrm{R} 134 \mathrm{a}$, and $\mathrm{CO}_{2}$. Table 5 lists the input data used to validate the mean-line model for the different test cases. In the analysis mode, the model was validated by assigning the actual geometry and comparing the performance for each test case. In the design mode, the design point specifications and the full impeller geometry were assigned, and the diffuser geometry was calculated to match the required stage pressure ratio.

\subsubsection{Air compressors}

The first three compressor test cases use air, and their experimental results are considered to be one of the most comprehensive experimental data sets for centrifugal compressors [57]. The three centrifugal compressors were extensively investigated in the past, and were named Eckardt compressors as they were tested by Dr. Dietrich Eckardt in the 1970s. The experimental investigations of Eckardt were published in a series of papers [58-60] and were performed using laser two-focus velocimetry, high-frequency pressure transducers, and conventional pneumatic probes.

The accuracy of the experimental data amounts to $\pm 1 \%$ for the mass flow rate, $\pm 3 \mathrm{rpm}$ in rotational speed, $\pm 0.07{ }^{\circ} \mathrm{C}$ in temperature for the baseline or $\pm 0.2{ }^{\circ} \mathrm{C}$ with recovery factor error, $\pm 2 \%$ on impeller exit or diffuser inlet area, $\pm 0.25 \%$ in nominal pressure or $\pm 0.5 \%$ for $r / r_{2}<1.1$ and angles to $\pm 0.25^{\circ}$ nominal or $\pm 0.5^{\circ}$ for $r / r_{2}<1.1$. These values were considered to be meeting or exceeding common research standards at that time [57].

\subsubsection{R134a compressor}

The fourth test case was a centrifugal compressor which was designed for domestic heat pump applications, and employed the refrigerant R134a. Due to the considered application, the use of a refrigerant, and the compressor size and type, this test case is particularly relevant to assess the suitability of the mean-line model using a refrigerant working fluid.

The compressor was recently designed and tested by Schiffmann and Favrat [11, 61-63]. Table 5 lists the geometrical and modeling details. The compressor could be tested at high rotational speeds and employed gas lubricated bearings, allowing for oil-free operation. The measurements were performed using different probes with an accuracy of $\pm 0.2 \mathrm{~K}$ in the temperature, \pm 0.002 $\mathrm{MPa}$ in the pressure, $\pm 0.5 \%$ in the mass flow rate, and $\pm 0.1 \%$ in the electric power [11]. The tests showed that the compressor could achieve values of pressure ratio up to 3.3 , power up to $1.8 \mathrm{~kW}$, rotational speed up to $210 \mathrm{krpm}$, and internal isentropic efficiency up to $79 \%$. No details of internal flow measurements were reported.

The experimental results proved the technical feasibility of a small-scale, oil-free and direct driven turbocompressor for domestic heat pump applications.

\subsection{3. $\mathrm{CO}_{2}$ compressor}

The fifth test case is a centrifugal compressor operating with supercritical $\mathrm{CO}_{2}$ and was tested by Wright et al. [64] at Sandia National Laboratories (SNL) under 
the framework of the development of advanced Brayton cycles using supercritical working fluids.

This test case is particularly relevant since the working fluid is used in the refrigeration field and there is the presence of highly challenging numerical modeling conditions close to the critical point, where the fluid properties exhibit large deviations from the ideal gas laws as well as large variations. The compressor stage consists of an impeller and a vaned diffuser. The rotor consists of six main blades and six splitter blades, whereas the diffuser consists of 17 wedge-shaped vanes. Table 5 shows the geometrical and modeling details. The compressor uses gas foil bearings, a high-speed permanent magnet motor/alternator and labyrinth gas seals to reduce the rotor cavity pressure. A small-scale loop was designed and the compressor was tested up to a rotational speed of $65 \mathrm{krpm}$, a pressure ratio of 1.65 and a mass flow rate of $1.8 \mathrm{~kg} / \mathrm{s}$. Wright et al. [64] documented values of accuracy for the experimental temperature probes of approximately $0.2 \mathrm{~K}$ for resistance thermometry devices, and $0.1 \mathrm{~K}$ for thermocouples. The test results obtained by Wright et al. [64] demonstrated the possibility of stable, controllable operation near the critical point.

In the validation, the results from the mean-line model are also compared to numerical simulations carried out to validate a CFD code documented in Pecnik et al. [65] for the impeller only and in Rinaldi et al. [66] for the impeller and vaned diffuser. The CFD code is representative of the current state-of-the-art for numerical modeling of centrifugal compressors operating with $\mathrm{CO}_{2}$, and therefore the CFD results were used as an additional benchmark for the validation of the mean-line model.

\subsection{Case study and cycle modeling}

The method used to design a HTHP equipped with a centrifugal compressor, was applied to the design of a high-temperature cycle of a cascade heat pump for steam generation. The heat pump was designed to supply industrial process steam at $150^{\circ} \mathrm{C}$, while utilizing heat supplied at $100^{\circ} \mathrm{C}$. The bottom cycle, not included in the present analysis, utilizes low-temperature heat sources such as excess heat or district heating while providing constant operating conditions to the top cycle.

Figure 4 depicts two investigated cycle layouts of the heat pump system. Layout (a) is an open-loop cycle in which the working fluid is the process steam itself. The steam is returned from the process as condensate, before being directly evaporated and compressed. The compression is realized in two stages, due to the comparatively high-pressure ratio (above 5) for steam. An in-
Table 3: Modeling conditions of the hightemperature heat pump cycle.

\begin{tabular}{lr}
\hline Parameter & Value Unit \\
\hline Evaporator & \\
$T_{\text {eva }}$ & $100{ }^{\circ} \mathrm{C}$ \\
$p_{\text {eva }}$ & $p_{\text {sat }}\left(T_{\text {eva }}\right) \mathrm{Pa}$ \\
Condenser & \\
$T_{\text {supply }}$ & $150{ }^{\circ} \mathrm{C}$ \\
$\Delta T_{\mathrm{pp}}$ & $3{ }^{\circ} \mathrm{C}$ \\
$p_{\text {cond }}$ & $p_{\text {sat }}\left(T_{\text {supply }}+\Delta T_{\mathrm{pp}}\right) \mathrm{Pa}$ \\
Subcooling (closed-loop only) & \\
$\Delta T_{\mathrm{sc}}$ & $5{ }^{\circ} \mathrm{C}$ \\
\hline
\end{tabular}

tercooler is included before the second-stage compressor inlet to realize a more efficient compression [67]. Layout (b) is a closed-loop, in which the working fluid is separated from the steam. The heat pump cycle is a one-stage cycle with an internal heat exchanger that preheats and evaporates the condensate before supplying the steam to the process.

Figure 4(a) shows also the use of an electric superheater before the first compressor stage, which was adopted as a safety measure to avoid the possible presence of two-phase conditions at the compressor inlet and outlet. In the open-loop cycle, the optimal pressure ratio of the two compressor stages was calculated as the geometric mean of the overall compression ratio. As opposed to the closed-loop cycle, the open-loop cycle can employ direct contact heat exchangers rather than surface heat exchangers, since the working fluid is the same as the steam supply.

Table 3 lists the modeling conditions of the thermodynamic cycle. The evaporation temperature of the heat pump (HP) cycle was $100{ }^{\circ} \mathrm{C}$, and the cycle supplied heat at a temperature of $150{ }^{\circ} \mathrm{C}$. A number of different working fluids were selected according to the following criteria: (i) subcritical cycle operation, (ii) no ozone depletion potential, (iii) low global warming potential $(<150)$, (iv) availability of the thermodynamic and transport properties in CoolProp [45] and/or REFPROP [46]. The selected working fluids were pentane, isopentane, cyclopentane, R1233zd(E), and MM. The latter is representative for siloxanes, which are considered to be possible working fluid candidates for future HTHP applications [68].

The compressor inlet temperature was determined by imposing a degree of superheat, which was calculated as the minimum temperature difference to avoid two-phase conditions at the compressor outlet. 


\subsection{Design optimization method}

The design model of the centrifugal compressor was coupled to that of a heat pump. Figure 5 shows the framework of the combined simulation and optimization. First, the heat pump cycle boundary conditions

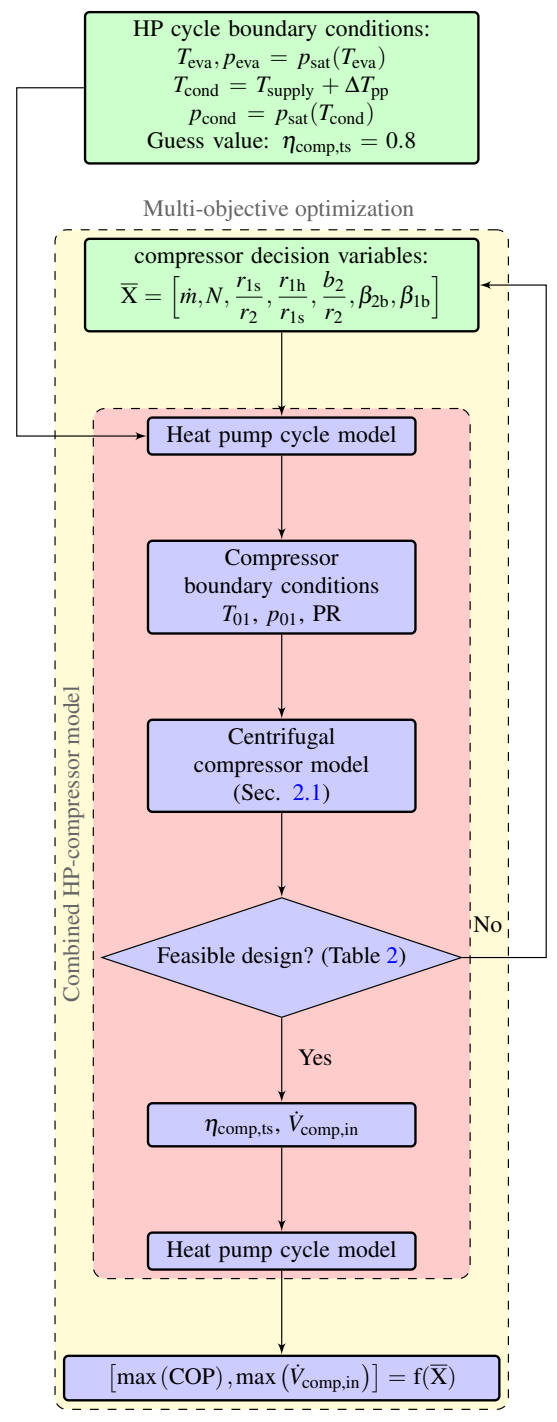

Figure 5: Method for the combined multi-objective optimization of the heat pump cycle and the centrifugal compressor.

were set as indicated in Table 2. An initial guess value of 0.8 for the compressor isentropic efficiency was assumed. The heat pump cycle and the compressor models were then combined (inner red marked area) and subsequently optimized (outer yellow area). The array $\bar{X}$ indicates the seven decision variables of the optimization. The mass flow rate of the compressor was used as a decision variable and was optimized together with the other decision variables to maximize the cycle coefficient of performance (COP) and the compressor inlet volume flow rate as follows:

$$
\begin{aligned}
& {\left[\max (\mathrm{COP}), \max \left(\dot{V}_{\text {comp,in }}\right)\right]=\mathrm{f}(\overline{\mathrm{X}})} \\
& \overline{\mathrm{X}}=\left[\dot{m}, N, \frac{r_{1 \mathrm{~s}}}{r_{2}}, \frac{r_{1 \mathrm{~h}}}{r_{1 \mathrm{~s}}}, \frac{b_{2}}{r_{2}}, \beta_{2 \mathrm{~b}}, \beta_{1 \mathrm{~b}}\right]
\end{aligned}
$$

Equations 36 and 37 show the mathematical relation between the cycle and the compressor models, which are interfaced through the mass flow rate and the compressor isentropic efficiency. The compressor inlet temperature and pressure, and the outlet pressure were governed by the thermodynamic cycle. Since the thermodynamic state at the compressor inlet is fixed by the cycle specifications, the maximization of the compressor inlet volume flow rate, $\dot{V}_{\text {comp,in, also corresponds to maximize }}$ the supplied heat flow rate.

The decision variables of Eq. 37 were varied by the optimizer within the boundaries listed in Table 2 until achieving a technically feasible and manufacturable design. The compressor impeller outlet diameter was fixed to the value of $110 \mathrm{~mm}$, which corresponds to that of the technology presented in Ref. [69] that focuses on similar heat pump applications. Fixing the compressor tip diameter allows comparing different solutions based on the same size, and makes it possible to compare with the state-of-the-art steam compressor of Ref. [69]. Since the compressor outlet diameter was fixed, the isentropic stage loading coefficient $\psi=\Delta h_{0, \text { is }} / U_{2}^{2}$ was readily calculated at the beginning of the routine and, therefore, was not optimized. The optimal number of blades was calculated using Eq. 1.

In the case of steam, where a two-stage compressor was required (see Sec. 2.5), the second stage was optimized assuming to be mounted on the same shaft as the first one, and the mass flow rate was calculated by mass and energy balances at the intercooler. As a result, a total of 12 decision variables was optimized in this case.

A multi-objective optimization was performed in MATLAB [44] and was based on a genetic algorithm using a population of 500 individuals and 200 generations. In the optimization of the two-stage steam compressor, a population of 1000 individuals was used instead due to the higher number of decision variables. 
Table 4: Loss correlations.

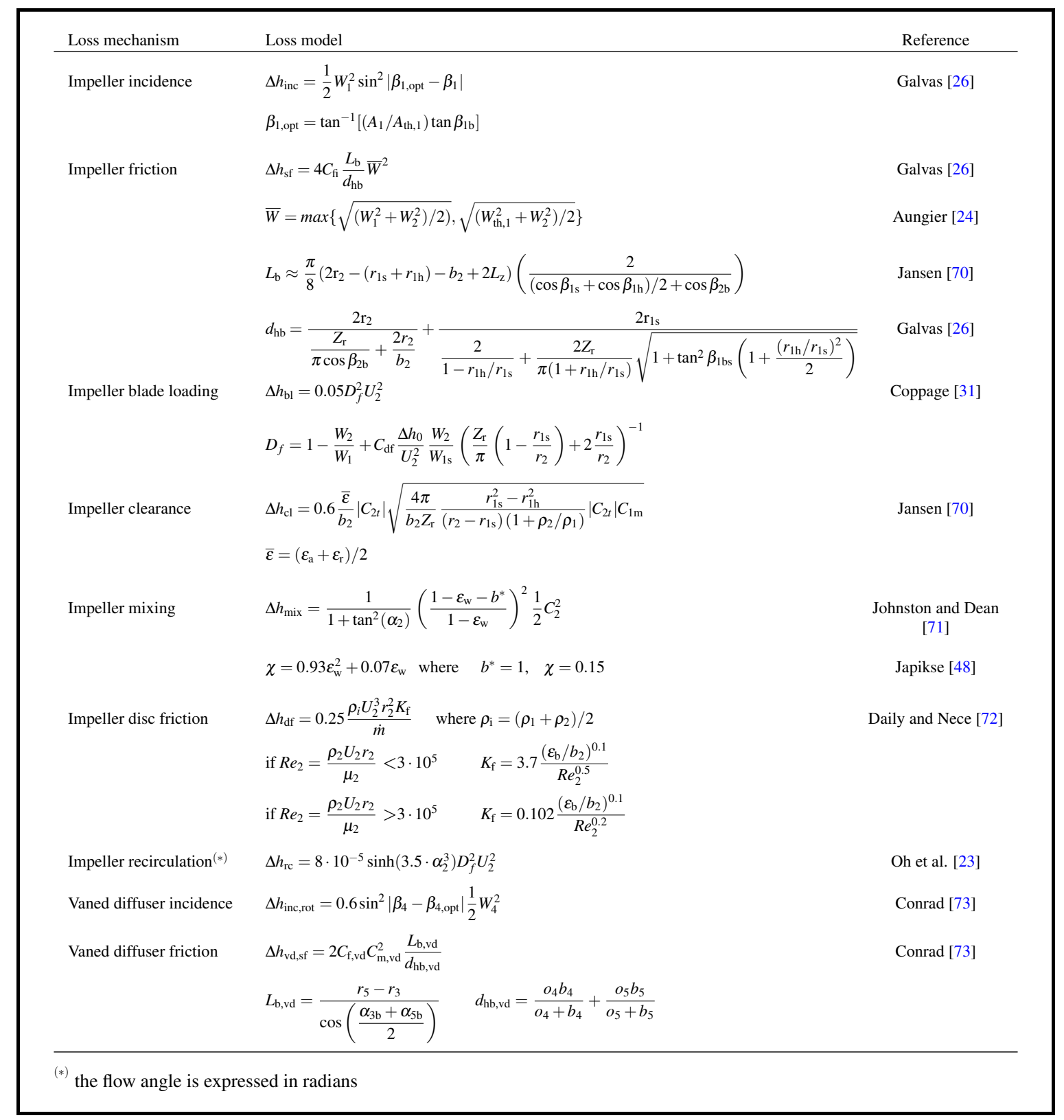


Table 5: Data of the experimental centrifugal compressors.

\begin{tabular}{|c|c|c|c|c|c|c|}
\hline \multicolumn{7}{|c|}{ Eckardt Impeller } \\
\hline & & $\mathrm{O}$ & A & B & Schiffmann and & Sandia \\
\hline Ref. & Units & {$[57-59,74]$} & {$[57-59,74]$} & {$[57-59,74]$} & $\begin{array}{c}\text { Favrat } \\
{[11,61,63,75,} \\
76]\end{array}$ & {$[21,64-66,77]$} \\
\hline \multicolumn{7}{|c|}{ Input conditions } \\
\hline Fluid & - & Air & Air & Air & R134a & $\mathrm{CO}_{2}$ \\
\hline$T_{01}$ & $\mathrm{~K}$ & 288.15 & 288.15 & 288.15 & 265 & 305.97 \\
\hline$p_{01}$ & bar & 1.01 & 1.01 & 1.01 & 1.65 & 76.9 \\
\hline$N$ & $\mathrm{krpm}$ & $14-16$ & $14-16$ & $14-16$ & $150-210$ & $45-55$ \\
\hline \multicolumn{7}{|c|}{ Impeller } \\
\hline$r_{1 \mathrm{~s}}$ & $\mathrm{~m}$ & 0.14 & 0.14 & 0.14 & 0.0056 & 0.0094 \\
\hline$r_{1 \mathrm{~h}}$ & $\mathrm{~m}$ & 0.045 & 0.06 & 0.0959 & 0.002 & 0.00254 \\
\hline$r_{2}$ & $\mathrm{~m}$ & 0.2 & 0.2 & 0.2 & 0.01 & 0.01868 \\
\hline$b_{2}$ & $\mathrm{~m}$ & 0.026 & 0.026 & 0.026 & 0.0012 & 0.00171 \\
\hline$L_{\mathrm{z}}$ & $\mathrm{m}$ & 0.13 & 0.13 & 0.13 & 0.007693 & 0.1137 \\
\hline$Z_{\mathrm{r}, \text { full }}$ & - & 20 & 20 & 20 & 9 & 6 \\
\hline$Z_{\mathrm{r}, \text { splitter }}$ & - & 0 & 0 & 0 & 9 & 6 \\
\hline $\mathrm{LR}_{\text {splitter }}$ & - & 0 & 0 & 0 & 0.5 & 0.7 \\
\hline$\beta_{1 \mathrm{bs}}$ & $\circ$ & -63 & -63 & -60 & -56 & -50 \\
\hline$\beta_{1 \mathrm{bh}}$ & $\circ$ & -32 & -40 & -45 & -30.23 & -40 \\
\hline$\beta_{2 \mathrm{~b}}$ & $\circ$ & 0 & -30 & -40 & -45 & -50 \\
\hline$\varepsilon_{\mathrm{a}}$ & $\mathrm{mm}$ & 0.372 & 0.235 & 0.372 & 0.15 & 0.254 \\
\hline$\varepsilon_{\mathrm{r}}$ & $\mathrm{mm}$ & 0.372 & 0.19 & 0.372 & 0.15 & 0.254 \\
\hline$\varepsilon_{\mathrm{b}}$ & $\mathrm{mm}$ & 0.372 & 0.235 & 0.372 & 1 & 0.254 \\
\hline$k_{s}$ & $\mathrm{~mm}$ & 0.002 & 0.002 & 0.002 & 0.01 & 0.01 \\
\hline$t_{\mathrm{b} 1}$ & $\mathrm{~mm}$ & 2.11 & 2.11 & 2.11 & 0.1 & 0.762 \\
\hline$t_{\mathrm{b} 2}$ & $\mathrm{~mm}$ & 1.08 & 1.08 & 1.08 & 0.1 & 0.762 \\
\hline \multicolumn{7}{|c|}{ Vaneless Diffuser } \\
\hline$r_{3} / r_{2}$ & - & 1.69 & 2.69 & 3.69 & 1.65 & 1.02 \\
\hline$b_{3} / b_{2}$ & - & 0.51 & 0.51 & 0.51 & 0.75 & 1 \\
\hline \multicolumn{7}{|c|}{ Vaned Diffuser } \\
\hline AR & - & - & - & - & - & 2.81 \\
\hline AS & - & - & - & - & - & 0.55 \\
\hline LWR & - & - & - & - & - & 3.41 \\
\hline$Z_{\mathrm{vd}}$ & - & - & - & - & - & 17 \\
\hline$\alpha_{3 \mathrm{~b}}$ & $\circ$ & - & - & - & - & 71.5 \\
\hline$\alpha_{5 \mathrm{~b}}$ & $\circ$ & - & - & - & - & 71.5 \\
\hline$t_{\mathrm{b} 3}$ & $\mathrm{~m}$ & - & - & - & - & 0 \\
\hline$t_{\mathrm{b} 5}$ & $\mathrm{~m}$ & - & - & - & - & 0.00335 \\
\hline$b_{5} / b_{2}$ & - & - & - & - & - & 1 \\
\hline$r_{5} / r_{2}$ & - & - & - & - & - & 1.37 \\
\hline \multicolumn{7}{|c|}{ Inducer } \\
\hline$r_{0}$ & $\mathrm{~m}$ & - & - & - & 0.01 & - \\
\hline$L_{\text {ind }}$ & $\mathrm{m}$ & - & - & - & 0.02 & - \\
\hline$k_{\mathrm{s}, \text { ind }}$ & $\mathrm{mm}$ & - & - & - & 0.1 & - \\
\hline \multicolumn{7}{|c|}{ Volute } \\
\hline$r_{4}$ & $\mathrm{~m}$ & - & - & - & 0.0045 & - \\
\hline
\end{tabular}




\section{Results}

\subsection{Validation}

Figure 6 shows the comparison between the measured and predicted pressure ratio and isentropic efficiency for the three Eckardt impellers [58-60].

The discrepancy in pressure ratio for impeller $\mathrm{O}$ is within $1.4 \%$. The model underestimates the actual pressure ratio of impeller $A$ by up to $6 \%$. In the case of impeller B, the highest discrepancy is seen at $16 \mathrm{krpm}$ and for both low and high mass flow rates, where the model has a deviation of up to $7 \%$. The prediction of the isentropic efficiency also follows the trends of the experimental measurements. The prediction for impeller A shows high accuracy, although the model does not reproduce the trend of the different speed lines perfectly. The maximum discrepancy is about $2 \%$-points. The efficiency predicted by impeller $\mathrm{A}$ is close to that of the actual case and, like for the pressure ratio, the efficiency results are underpredicted by up to $2 \%$-points at the best efficiency point, whereas the discrepancy is up to $6.7 \%$-points at higher values of mass flow rate. A similar trend is observed for impeller B; however, in this case, the model predicts the peak of the efficiency curves to be at $10 \%$ to $19 \%$ lower mass flow rate than the experimental peak value. Overall, the trend of the speed lines for both the pressure ratio and the efficiency with the mass flow rate is respected in all cases, indicating that the present model can predict the compressor behavior with consistency.

Figure 7 shows the comparison between the measured and the predicted pressure ratio for the compressor operated with R134a. In general, the agreement between the experimental data and the present model is relatively good considering the challenges related to modelling accurately mini and micro-scale turbomachinery (the maximum shaft power of the compressor is about 1.5 $\mathrm{kW})$. The highest discrepancy was found at the lowest and highest values of the rotational speed, and close to the choking point where deviations in the pressure ratio up to $7 \%$ were found. Nevertheless, the model seems to capture the trend of the experimental results well. A higher deviation is found in the prediction of the compressor isentropic efficiency, see Figure 7(b). The highest deviation is found close to the onset of surge and of choking, indicating that the presence of inlet recirculation flows close to surge is the main cause for the discrepancy between numerical and experimental data. In Figure 7(b), the error bars related to the efficiency computed from the measurements of temperature and pressure are added as a reference. The error bars were extrapolated from Refs. $[11,76]$, where they were cal- culated using the error propagation approximated by a first-order Taylor series. The experimental uncertainty in the compressor isentropic efficiency was only available for this validation test case. For some speed lines, the model prediction is within the error band of the experimental data, and in other cases, the deviation is up to $8 \%$-points. Similar results were obtained by Schiffmann [76] and Schiffmann and Favrat [11], who showed deviations up to $8 \%$-points using their $1 \mathrm{D}$ model validated with the same test case.

Figure 8 shows the validation with the Sandia [21, 64-66, 77] compressor both for the 1D model and CFD calculations. The mean-line model generally shows good agreement with the experimental trends, with a maximum deviation of $15 \%$ in the enthalpy rise and $3.5 \%$-points in the efficiency. However, a higher deviation up to $17 \%$ in the enthalpy rise is observed at $55 \mathrm{krpm}$ as well as a shift of the peak efficiency from a flow coefficient of 0.03 to 0.04 , corresponding to a 25 $\%$ deviation. The CFD results also show a shift towards lower flow coefficients, especially at the low values of rotational speed, of about $25 \%$ compared to the experimental data. Rinaldi et al. [66] argued that such results are in a reasonable range of accuracy considering the challenges of CFD modeling close to the critical point of $\mathrm{CO}_{2}$.

Table 6 shows the results of the validation of the design model. The average deviation of the isentropic efficiency is within $5 \%$ for the Eckardt impellers, while it goes up to approximately $7 \%$ for the test case using $\mathrm{R} 134 \mathrm{a}$. Regarding the geometry, the diffuser radius ratio was found to be higher in the test cases of the Eckardt [57-59, 74] impellers A and B and of the R134a compressor, the latter showing the largest increase from 1.65 to 2.23, indicating that higher losses are predicted for these cases. These results are in agreement with those found for the off-design validation and further confirm that the model is suitable for the preliminary design of centrifugal compressors using different working fluids.

\subsection{Compressor design optimization}

Figure 9 shows the Pareto fronts of the optimal solutions after the multi-objective optimization for the different working fluids and in terms of COP and supply heat flow rate. The point corresponding to an equal weight of both the objective functions is selected as the best solution in the Pareto front and is indicated with the red dot. The shape of the Pareto fronts is for some fluids rather pronounced. This characteristic stems mainly from the values of the mass flow rate, which for each point in the Pareto front results as a trade-off regarding 


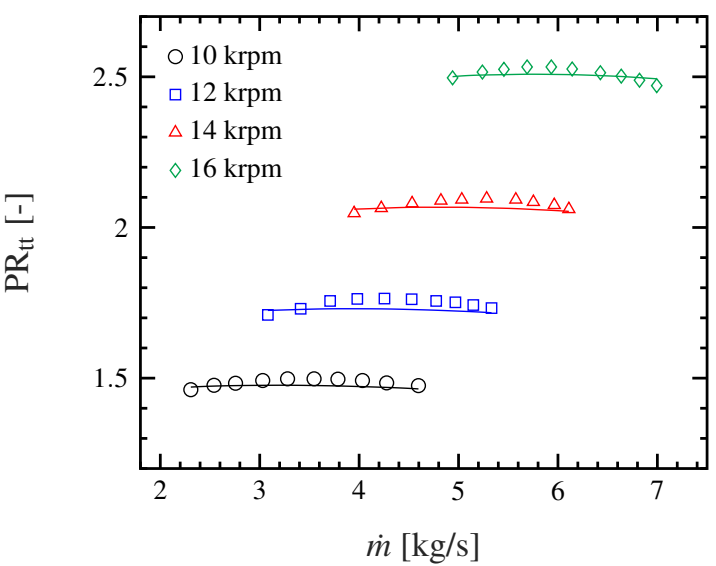

(a)

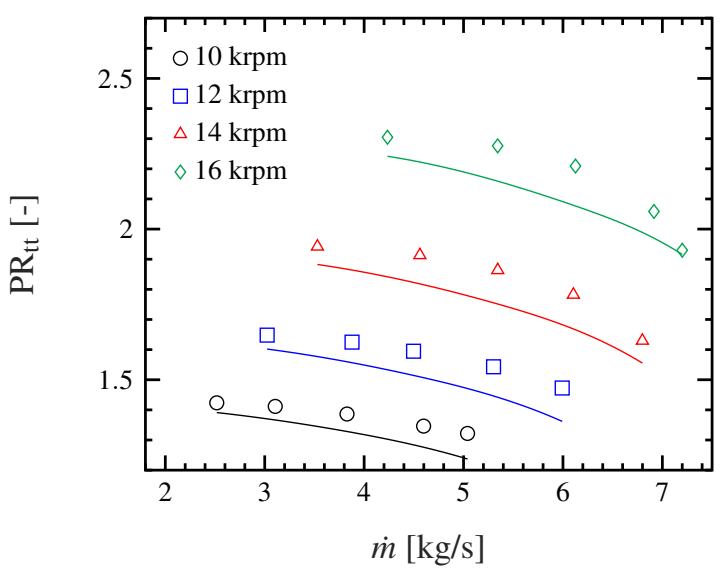

(c)

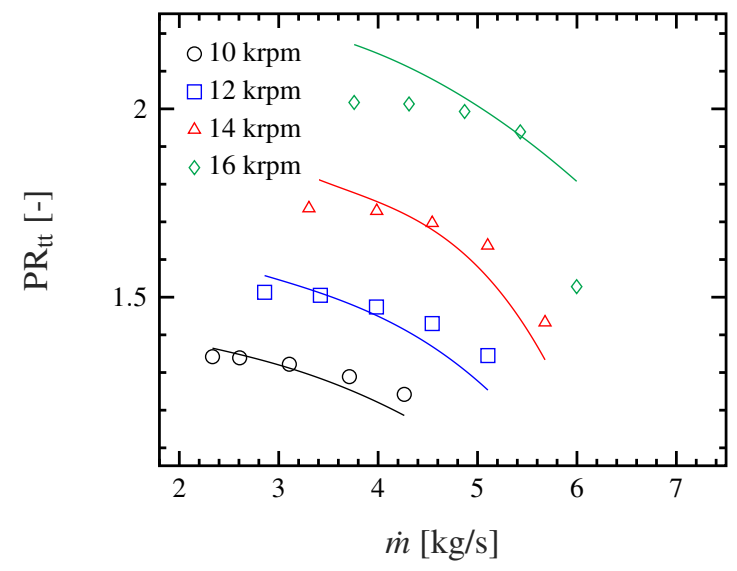

(e)

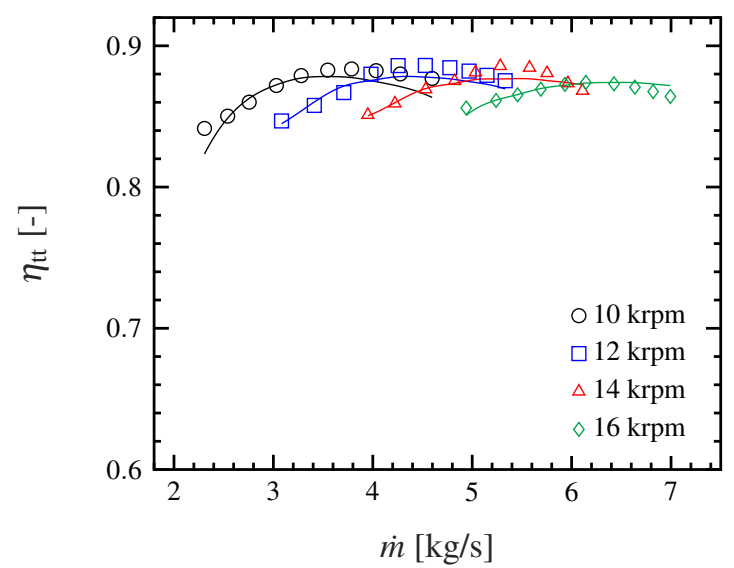

(b)

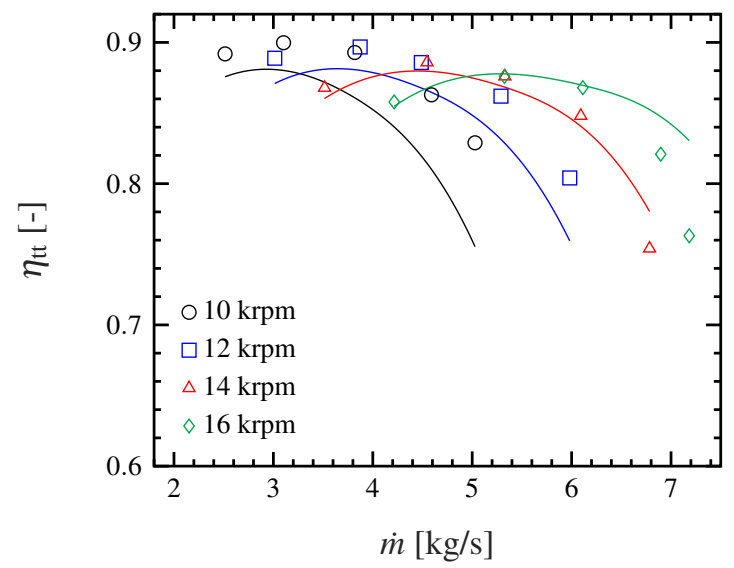

(d)

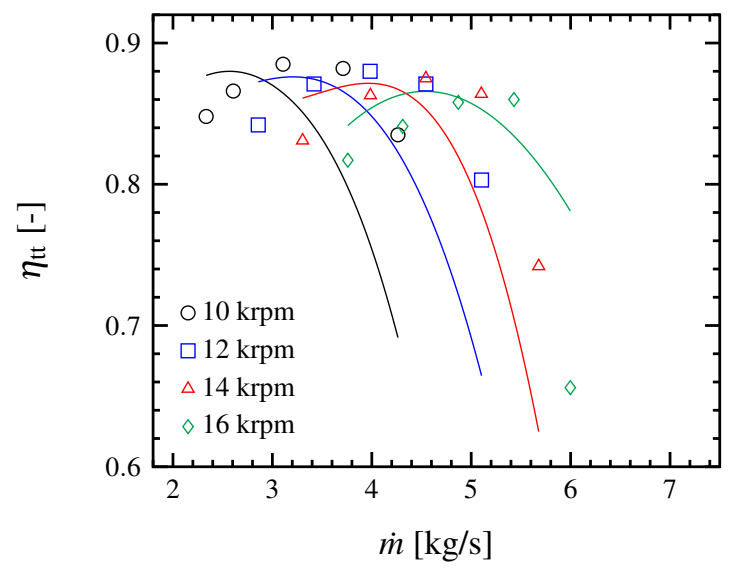

(f)

Figure 6: Comparison between the measured $(0)$ and predicted (-) pressure ratio and isentropic efficiency for different Eckardt impellers [58-60]: (a,b) impeller O; (c,d) impeller A; (e,f) impeller B. 


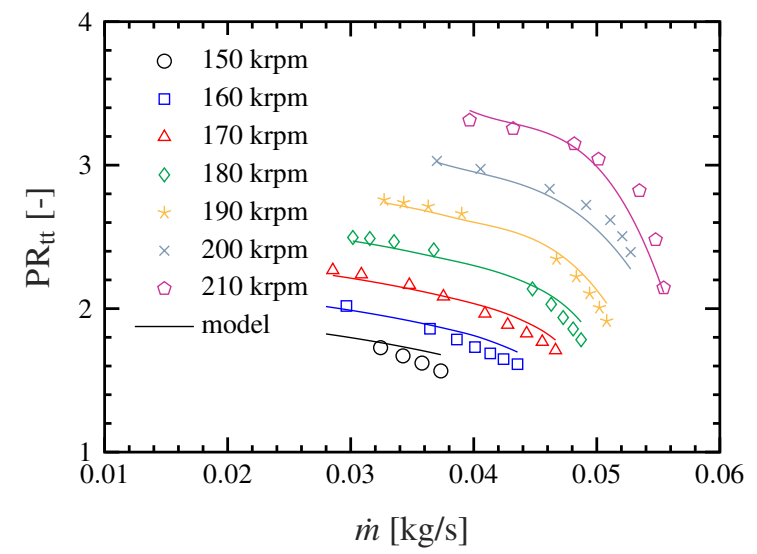

(a)

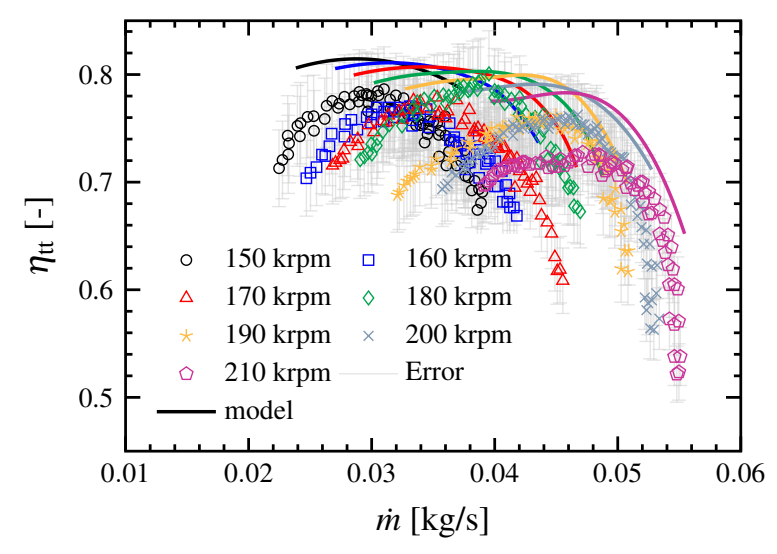

(b)

Figure 7: Comparison between the measured and predicted results for the compressor operated with R134a and studied by Schiffmann and Favrat [11, 76]: (a) pressure ratio and (b) isentropic efficiency.

cycle performances and the minimum mass flow rate required to avoid choking in the compressor impeller.

In terms of cycle performance, the Pareto front for steam achieves the highest value of COP and supply heat flow rate, respectively, 5.46 and $1.73 \mathrm{MW}$ at the best point. The fluid cyclopentane has the second highest value of COP of 4.74, but delivers 1.22 MW, corresponding to a $30 \%$ lower supply heat flow rate. The working fluid MM has a lower value of COP, around 4.54 , but also supplies the lowest value of heat flow rate with approximately $0.24 \mathrm{MW}$. The fluids n-pentane and isopentane exhibit lower values of cycle COP, but values of heat flow rate higher than cyclopentane and about $19 \%$ and $6 \%$ less than steam, respectively. Finally, R1233zd(E) shows the lowest value of COP and a $57 \%$
Table 6: Validation of the design model.

\begin{tabular}{|c|c|c|c|c|c|}
\hline \multirow[b]{2}{*}{ Refs. } & \multicolumn{3}{|c|}{ Eckardt compressors } & \multirow[b]{2}{*}{$\begin{array}{c}\text { Schiffmann } \\
{[11,61,} \\
63,75,76]\end{array}$} & \multirow[b]{2}{*}{$\begin{array}{c}\text { Sandia } \\
{[21,64-} \\
66,77]\end{array}$} \\
\hline & $\begin{array}{c}\mathrm{O} \\
{[57-} \\
59,74]\end{array}$ & $\begin{array}{c}\text { A } \\
{[57-} \\
59,74]\end{array}$ & $\begin{array}{c}\text { B } \\
{[57-} \\
59,74]\end{array}$ & & \\
\hline No & 1 & 2 & 3 & 4 & 5 \\
\hline$P R_{t t}[-]$ & 2 & 1.81 & 1.67 & 2.35 & 1.26 \\
\hline$\dot{m}[\mathrm{~kg} / \mathrm{s}]$ & 5.32 & 4.54 & 4.54 & 0.039 & 2.15 \\
\hline$N[\mathrm{krpm}]$ & 14 & 14 & 14 & 180 & 50 \\
\hline$\psi_{i s}$ & 0.78 & 0.62 & 0.53 & 0.5 & 0.41 \\
\hline $\begin{array}{lr}\begin{array}{l}\text { Diffuser } \\
\text { dius }\end{array} & \text { ra- } \\
\text { (model) } & \end{array}$ & 1.69 & 1.80 & 1.88 & 2.23 & 1.37 \\
\hline $\begin{array}{lr}\text { Diffuser ra- } \\
\text { dius ratio } \\
\text { (actual) }\end{array}$ & 1.69 & 1.69 & 1.69 & 1.65 & 1.3697 \\
\hline$\eta_{\text {model }}$ & 0.885 & 0.869 & 0.843 & 0.744 & 0.717 \\
\hline$\eta_{\exp }$ & 0.886 & 0.876 & 0.875 & 0.800 & 0.673 \\
\hline deviation & $-0.03 \%$ & $-0.84 \%$ & $-3.70 \%$ & $-7.03 \%$ & $6.52 \%$ \\
\hline
\end{tabular}

lower supply heat flow rate of steam, respectively, 3.86 and $742.6 \mathrm{~kW}$.

Figure 9(b) shows the Pareto fronts regarding compressor total-to-static efficiency and inlet volume flow rate. In this case, the steam compressor can accept the highest inlet volume flow rate, approximately 1.07 $\mathrm{m}^{3} / \mathrm{s}$, but at the expense of the lowest values of total-tostatic isentropic efficiency in the two stages, about 0.69 and 0.68 in the first and the second stage, respectively. The opposite trend is seen for the other fluids which feature a higher value of compressor isentropic efficiency and a lower value of inlet volume flow rate.

Table 7 lists the results of the design optimization, and Figure 10 shows the meridional cut layout of the obtained compressors. The optimal value of mass flow rate varies significantly among the different fluids: the highest value of $7.85 \mathrm{~kg} / \mathrm{s}$ is found for R1233zd(E) and the lowest value for steam with $0.64 \mathrm{~kg} / \mathrm{s}$ in the first stage. The optimal rotational speed is also very different and ranges from approximately $28.8 \mathrm{krpm}$ for R1233zd(E) to $85 \mathrm{krpm}$ for steam. Considering the fixed impeller diameter of $110 \mathrm{~mm}$, such values of rotational speed result in acceptable values of impeller tip peripheral speed, which are well below the limit value of $500 \mathrm{~m} / \mathrm{s}$. However, values close to this limit are found for the twostage steam compressor and stem directly from the high value of rotational speed.

The seven compressors have a significant backsweep, above $40^{\circ}$ for all fluids except for the steam compressor, where the exit blades tend to be of the radial type. The optimal solutions were found at the upper limit of $r_{1 s} / r_{2}$ for all hydrocarbons and the first stage with steam. All compressor stages, except for those with R1233zd(E) 


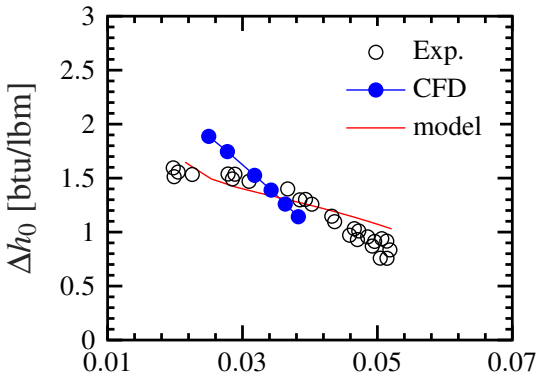

(a) $45 \mathrm{krpm}$

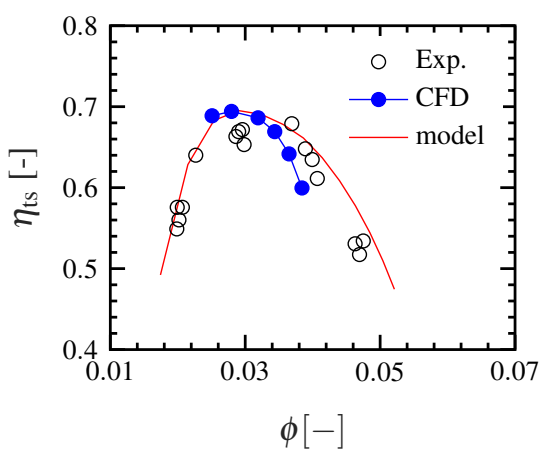

(d) $45 \mathrm{krpm}$

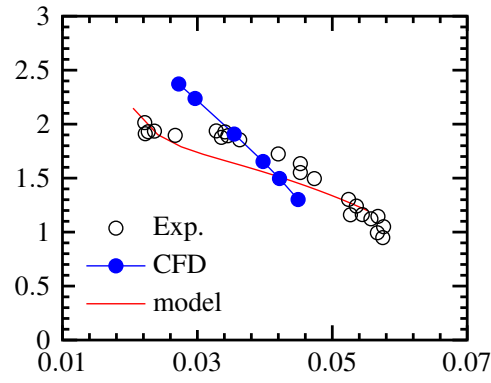

(b) $50 \mathrm{krpm}$

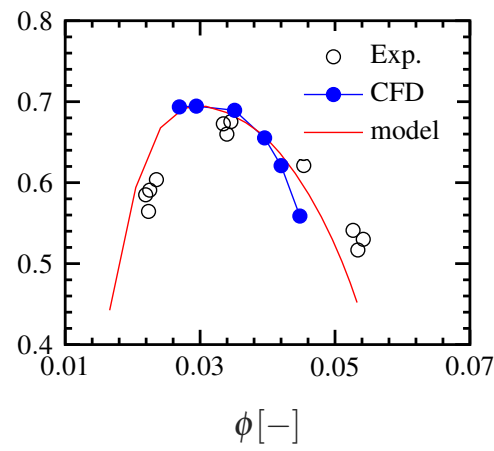

(e) $50 \mathrm{krpm}$

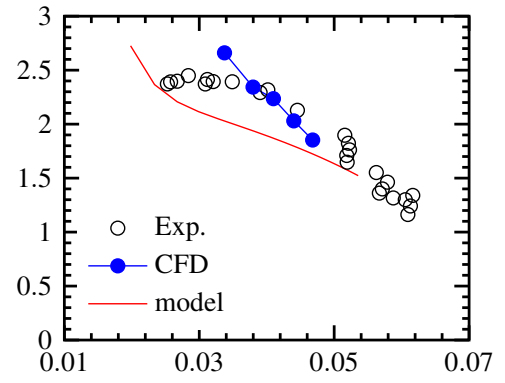

(c) $55 \mathrm{krpm}$

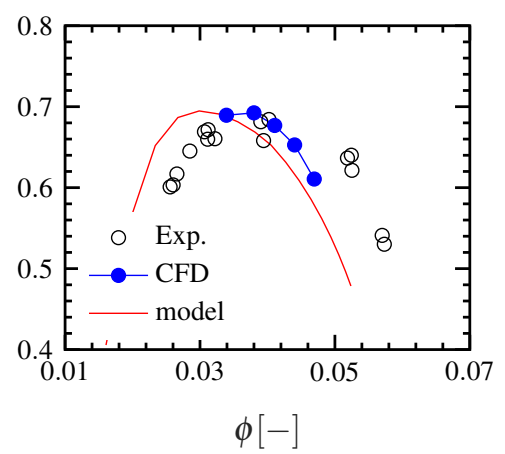

(f) $55 \mathrm{krpm}$

Figure 8: Comparison between the measured and the predicted enthalpy rise and isentropic total-to-static efficiencyas a function of the flow coefficient $\phi=\dot{\mathbf{m}} /\left(\rho_{01} \mathbf{U}_{2} \mathbf{d}_{2}^{2}\right)$ for the Sandia compressor impeller with vaned diffuser. Experimental data from Ref. [64] and state-of-the-art CFD data from Ref. [66].

and the second stage with steam, feature a high fluid dynamic loading and high values of relative Mach number at the inlet, $\mathrm{M}_{1 \mathrm{~s} \text {,rel }}$, which exceed unity at the shroud.

The throat dimensions of all geometries are between $4.1 \mathrm{~mm}$ and $7.4 \mathrm{~mm}$, enabling that they can be manufactured using a conventional five-axis milling machine. All of the designs feature a similar number of blades, between 18 and 22, for the same tip diameter. This suggests that they will have similar costs.

Finally, the fluid R1233zd(E) resulted in the highest values of total-to-total and total-to-static efficiency of approximately 0.91 and 0.79 , respectively. These values are about $10 \%$-points higher than those of steam. Despite the large differences in the isentropic efficiency, steam still holds the highest value of COP due to advantages in the cycle layout.

\section{Discussion}

The validation with the five test cases suggests that the model can predict the performance of different compressor types with reasonable accuracy under different thermodynamic conditions and applications, from the ideal gas flows of industrial air compressors to real-gas and dense flow conditions in refrigeration or $\mathrm{CO}_{2}$ applications.

The results of the optimization with the heat pump cycle suggest that the open-loop using steam yields the highest performance in terms of COP and $\dot{V}_{\text {comp,in }}$, and it is therefore the preferred choice among all the considered working fluids for the HTHP. Finally, the results of the combination of cycle and compressor models suggest that, in the case of mechanical design issues of steam compressors or if a single-stage compressor is preferred to reduce the investment cost, a closed-loop HTHP with cyclopentane gives the second best option, although at the expense of a lower COP and supplied heat flow rate. In this case, a lower optimal rotational speed of $48 \mathrm{krpm}$ is employed, thereby reducing the mechanical stresses on the impeller blades and yielding higher values of compressor isentropic efficiency.

Previous works [32-37] focused on the working fluid selection for heat pump applications by assuming a fixed value of isentropic efficiency. The thermodynamic 
Table 7: Optimal compressor design for different working fluids.

\begin{tabular}{|c|c|c|c|c|c|c|c|c|}
\hline Parameter & Units & Pentane & Isopentane & Cyclopentane & R1233zd(E) & MM & $\begin{array}{c}\text { Steam } \\
\text { (stage 1) }\end{array}$ & $\begin{array}{c}\text { Steam } \\
\text { (stage 2) }\end{array}$ \\
\hline$T_{01}$ & $\mathrm{~K}$ & 391.2 & 390.4 & 387.1 & 376.2 & 406.9 & 373.2 & 397.7 \\
\hline$p_{01}$ & bar & 59.27 & 7.22 & 4.16 & 10.42 & 1.00 & 1.01 & 2.29 \\
\hline $\mathrm{PR}_{\mathrm{tt}}$ & - & 2.828 & 2.721 & 2.965 & 2.765 & 3.745 & 2.255 & 2.255 \\
\hline$\dot{m}$ & $\mathrm{~kg} / \mathrm{s}$ & 5.73 & 7.45 & 3.88 & 7.85 & 1.30 & 0.64 & 0.69 \\
\hline$N$ & $\mathrm{rpm}$ & 46000 & 43985 & 48000 & 28802 & 34000 & 85001 & 85001 \\
\hline$r_{1 \mathrm{~s}} / \mathrm{r}_{2}$ & - & 0.70 & 0.70 & 0.70 & 0.53 & 0.70 & 0.70 & 0.68 \\
\hline$r_{1 \mathrm{~h}} / \mathrm{r}_{1 \mathrm{~s}}$ & - & 0.33 & 0.27 & 0.34 & 0.32 & 0.29 & 0.26 & 0.64 \\
\hline$b_{2} / \mathrm{r}_{2}$ & - & 0.14 & 0.18 & 0.17 & 0.11 & 0.19 & 0.27 & 0.12 \\
\hline$\beta_{2 \mathrm{~b}}$ & $\circ$ & -43.6 & -44.8 & -44.7 & -43.1 & -44.91 & -13.05 & -5.16 \\
\hline$\beta_{1 \mathrm{~b}}$ & $\circ$ & -45.1 & -47.7 & -49.7 & -34.5 & -50.6 & -34.3 & -44.6 \\
\hline$T_{03}$ & $\mathrm{~K}$ & 428.9 & 429.1 & 430.4 & 429.6 & 429.9 & 476.1 & 504.6 \\
\hline$U_{2}$ & $\mathrm{~m} / \mathrm{s}$ & 264.9 & 253.3 & 276.5 & 165.9 & 195.8 & 489.6 & 489.6 \\
\hline$C_{3}$ & $\mathrm{~m} / \mathrm{s}$ & 105.9 & 88.4 & 118.7 & 67.6 & 81.0 & 199.3 & 212.6 \\
\hline$\beta_{2}$ & $\circ$ & -53.2 & -55.3 & -55.0 & -55.1 & -57.3 & -33.5 & -25.0 \\
\hline$\alpha_{2}$ & $\circ$ & 65.7 & 70.1 & 70.6 & 72.2 & 76.7 & 69.2 & 67.2 \\
\hline$M_{1 \mathrm{~s}, \mathrm{rel}}$ & - & 1.09 & 1.08 & 1.08 & 0.84 & 1.03 & 1.02 & 0.85 \\
\hline$M_{1, \mathrm{rel}}$ & - & 0.89 & 0.88 & 0.88 & 0.71 & 0.81 & 0.88 & 0.76 \\
\hline$M_{2, \text { rel }}$ & - & 0.69 & 0.61 & 0.56 & 0.55 & 0.46 & 0.35 & 0.37 \\
\hline$M_{2}$ & - & & 1.02 & 0.97 & 1.02 & 1.08 & 0.83 & 0.86 \\
\hline$r_{1 \mathrm{~s}}$ & $\mathrm{~m}$ & 0.0385 & 0.0384 & 0.0384 & 0.0291 & 0.0371 & 0.0384 & 0.0371 \\
\hline$r_{1 \mathrm{~h}}$ & $\mathrm{~m}$ & 0.0127 & 0.0105 & 0.0131 & 0.0094 & 0.0106 & 0.0098 & 0.0236 \\
\hline$r_{2}$ & $\mathrm{~m}$ & 0.0550 & 0.0550 & 0.0550 & 0.0550 & 0.0550 & 0.0550 & 0.0550 \\
\hline$L_{z}$ & $\mathrm{~m}$ & 0.0360 & 0.0391 & 0.0353 & 0.0276 & 0.0371 & 0.0401 & 0.0189 \\
\hline$b_{1}$ & $\mathrm{~m}$ & 0.0257 & 0.0279 & 0.0252 & 0.0197 & 0.0265 & 0.0286 & 0.0135 \\
\hline$b_{2}$ & $\mathrm{~m}$ & 0.0079 & 0.0099 & 0.0093 & 0.0058 & 0.0085 & 0.0147 & 0.0065 \\
\hline$b_{3}$ & $\mathrm{~m}$ & 0.0079 & 0.0099 & 0.0093 & 0.0058 & 0.0085 & 0.0147 & 0.0065 \\
\hline$Z_{r}$ & - & 19 & 19 & 20 & 19 & 22 & 18 & 18 \\
\hline$Z_{\mathrm{r}, \text { splitter }}$ & - & 0 & 0 & 0 & 0 & 0 & 0 & 0 \\
\hline$r_{3}$ & $\mathrm{~m}$ & 0.0735 & 0.0836 & 0.0738 & 0.0738 & 0.0735 & 0.1016 & 0.0996 \\
\hline$o_{1}$ & $\mathrm{~m}$ & 0.0058 & 0.0052 & 0.0050 & 0.0051 & 0.0041 & 0.0068 & 0.0074 \\
\hline DR & - & 0.755 & 0.738 & 0.764 & 0.748 & 0.743 & 0.704 & 0.636 \\
\hline$\eta_{\mathrm{ts}}$ & - & 0.764 & 0.759 & 0.750 & 0.788 & 0.697 & 0.693 & 0.686 \\
\hline$\eta_{\mathrm{tt}}$ & - & 0.892 & 0.851 & 0.886 & 0.907 & 0.838 & 0.796 & 0.797 \\
\hline $\mathrm{COP}$ & - & 4.38 & 4.18 & 4.74 & 3.86 & 4.54 & \multicolumn{2}{|c|}{5.46} \\
\hline$\dot{V}_{\text {in }}$ & $\mathrm{m}^{3} / \mathrm{s}$ & 0.38 & 0.40 & 0.39 & 0.14 & 0.26 & \multicolumn{2}{|c|}{1.07} \\
\hline$\dot{Q}_{\text {supply }}$ & $\mathrm{kW}$ & 1406 & 1626 & 1225 & 743 & 242 & \multicolumn{2}{|c|}{1734} \\
\hline
\end{tabular}




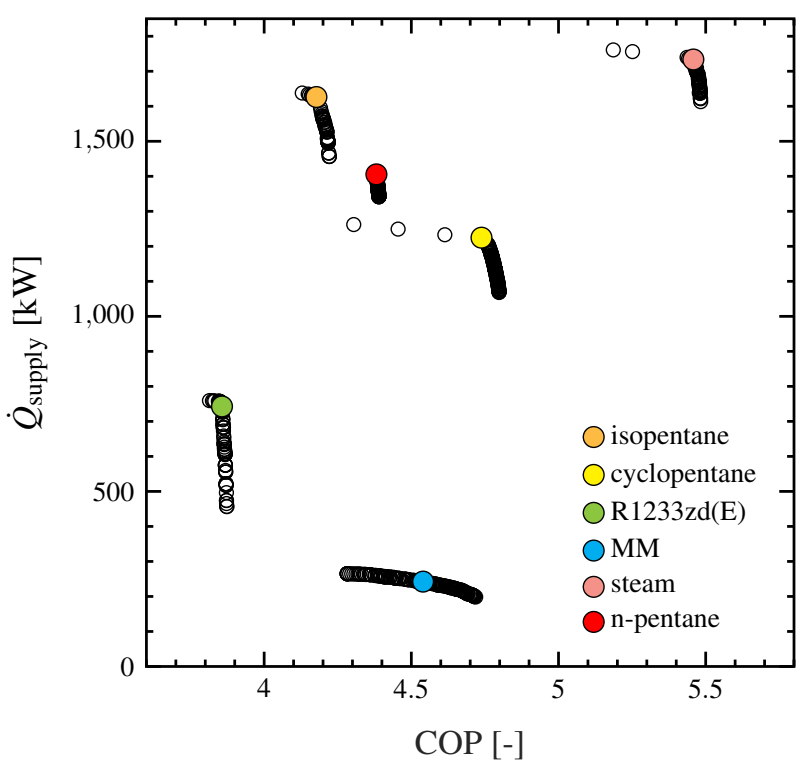

(a)

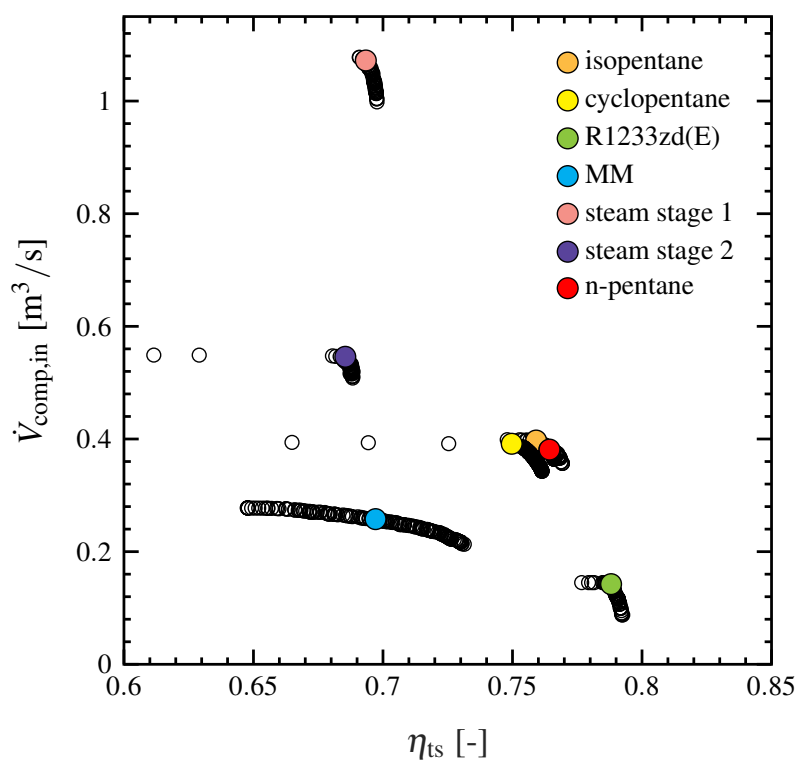

(b)

Figure 9: Pareto fronts of the optimal solutions for the selected working fluids: (a) COP and supply heat flow rate; (b) compressor isentropic efficiency and inlet volume flow rate. The solution having an equal weight of the two objective functions is indicated with the symbol $O$.

cycle performance was analyzed in terms of COP and of the volumetric heating capacity. The latter was used as an indication of the volume flow rate at compressor inlet, and thereby the size of the compressor, for the same supply heat flow rate. This procedure assumes that the volume flow rate at the inlet of the compressor is directly related to the size of the compressor. However, the results of the present study suggest that volume flow rates in the range $0.1 \mathrm{~m}^{3} / \mathrm{s}$ to $1.0 \mathrm{~m}^{3} / \mathrm{s}$ can be achieved with a compressor of comparable size and suggest that the actual volume flow rate depends on additional aspects such as the compressor stage pressure ratio, the maximum mass flow rate, the rotational speed and the working fluid itself. For the same reasons, the results of this study also suggest that the volumetric heating capacity (supplied heat flow rate over compressor inlet volume flow rate) might not be the most suitable indicator for estimating the size and, therefore, the cost of the centrifugal compressor.

This aspect further highlights the importance of applying a mean-line model together with that of the HP cycle. Moreover, the variation of the isentropic efficiency for the different fluids substantiates the relevance of the presented method, since it can represent the tradeoff in terms of heat capacity and COP, while providing reasonable estimates for volume flow rates and isen- tropic efficiencies.

The results highlight that the use of steam also requires a more challenging and expensive compressor design. The high value of rotational speed produces high-velocity flows in the impeller and diffuser passages, and requires low values of mass flow rate, leading to lower values of isentropic efficiency. For this reason, the design of a high-efficiency compressor for steam is a fluid-dynamic and technical challenge. Compared to the other fluids, the steam compressor may also experience supersonic shock losses at the inlet and mechanical resistance issues associated to the high values of peripheral speed in the impeller. In addition, the presence of two compression stages, required to deliver a pressure ratio above 5, represents a higher investment cost in the overall system. Nevertheless, this may be compensated by the absence of surface heat exchangers and the higher system COP.

The optimal design of the steam compressor obtained in this work, features a rotational speed of $85 \mathrm{krpm}$, a peripheral speed of approximately $490 \mathrm{~m} / \mathrm{s}$, blade angles in the range $-15^{\circ}$ to $-5^{\circ}$, transonic flow conditions at the compressor inlet with relative Mach numbers in the range 0.76 to 1.02 , and values of total-tostatic isentropic efficiency of about 0.69 . These results agree with those presented in the literature. Šarevski 


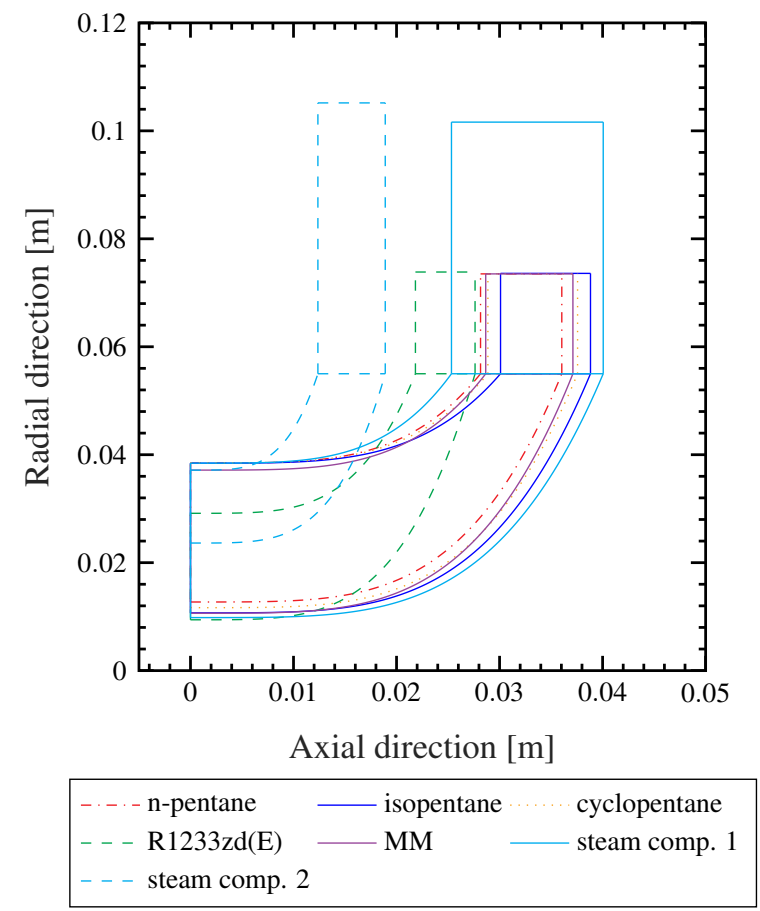

(a)

\section{Figure 10: Meridional cut layout of the optimal com- pressor designs.}

and Šarevski [78] analyzed the characteristics of a centrifugal compressor for steam applied in refrigeration and heat pump systems. They found that a pressure ratio of approximately 3.5 is the limiting value for a single stage, and for a temperature lift of $20^{\circ} \mathrm{C}$ to $45^{\circ} \mathrm{C}$ they found that a two-stage compressor is the optimal solution. This design philosophy is confirmed in this work, as the single-stage compressor design using the mean-line model results in excessive values of peripheral speed, supersonic Mach numbers and choking conditions inside the blade channels. In Ref. [78] the optimal blade angles at the impeller exit were found to be in the range $-15^{\circ}$ to $0^{\circ}$ with a Mach number at the impeller inlet in the range 0.85 to 0.95 . These values are in agreement with those of the present designs.

Madsbøll et al. [69] presented the construction and initial tests of a high-speed centrifugal compressor for a HTHP using steam as the working fluid. The authors designed the compressor at the speed of $95 \mathrm{krpm}$ with blade exit angles of $-10^{\circ}$. They showed a maximum value of compressor efficiency of 0.719 at the rotational speed $84.4 \mathrm{krpm}$, which is about $2.9 \%$-points higher than that predicted in the present work. In the context of refrigeration applications, Süß [14] recently presented a chiller module using a centrifugal compressor which was able to achieve a COP of 14 , considered to be 3 to 4 times higher than state-of-the-art equipment in the field. The compressor was designed to operate at $90 \mathrm{krpm}$ and demonstrated an overall efficiency, including the motor, of $70 \%$, which is close to the values of the optimal compressor in this paper.

Bantle [79] presented the test results for a prototype centrifugal compressor retrofitted from a turbocharger unit to be used for mechanical vapor recompression in steam driers. The centrifugal compressor was designed to deliver a thermal capacity of up to $300 \mathrm{~kW}$, and tests were conducted for an inlet temperature of $105^{\circ} \mathrm{C}$. At full capacity, the turbocompressor operated at $90 \mathrm{krpm}$ and achieved a pressure ratio of 2.4 with an isentropic efficiency of $72 \%$, a mass flow rate of $0.125 \mathrm{~kg} / \mathrm{s}$ and an outlet temperature of $225^{\circ} \mathrm{C}$.

The test conditions are similar to those of the firststage steam compressor from the mean-line model. The efficiency of Ref. [79] is predicted to be $3 \%$-points lower, and the mass flow rate is about 5.1 times smaller than the value $0.64 \mathrm{~kg} / \mathrm{s}$ found using the optimization method. However, the different value of mass flow rate is justified by the different value of supply heat load, which in this work is maximized and found to be 5.7 times greater than the $300 \mathrm{~kW}$ required by Bantle [79].

More recently, the same author [80] presented the design of a two-stage compressor which is a continuation of the previous work in Ref. [79]. The two impellers feature characteristics similar to those in Table 7. The optimal pressure ratio was 2 in the first stage and 3.2 in the second stage, and it was distributed unevenly between the stages. As a result, the first-stage impeller featured an inlet relative Mach number of 1.27 at the tip, and the second impeller a Mach number of 0.96. In the optimal compressor design of the present work, the equal distribution of the pressure ratio across the stages yields a maximum value of relative Mach number of 1.02 .

In terms of geometry, the two impellers presented in Ref. [80] featured exducer diameters of $115 \mathrm{~mm}$ and $146 \mathrm{~mm}$, respectively. These values are different from the value employed in this work $(110 \mathrm{~mm})$ since the two turbocompressors were designed for two separate values of stage pressure ratio.

The comparison with the aforementioned works, demonstrating similar values of fluid dynamic parameters and compressor performance among the studies, indicates that the method presented in the current paper is suitable. 


\section{Conclusions}

This paper presented a mean-line model for the design, optimization and analysis of centrifugal compressors and heat pump systems. The suitability of a meanline centrifugal compressor model and its loss correlations, was assessed for different working fluids and geometries. Moreover, a novel method for the design and optimization of a heat pump cycle equipped with a centrifugal compressor was presented. Such a method aims to determine technically feasible solutions from the compressor and heat pump viewpoints. This approach is intended to facilitate engineers and researchers in identifying cost-effective solutions for the next-generation heat pump designs.

The compressor model was validated at design and off-design conditions with the experimental data of five test cases including three different working fluids: air, $\mathrm{R} 134 \mathrm{a}$, and $\mathrm{CO}_{2}$. The off-design model showed deviations with the measured data up to $7 \%$ in the mass flow rate and $8 \%$-points in efficiency. Overall, the model captured the trend of the experimental results. The design model was validated within $7 \%$ in the compressor isentropic efficiency. The validation suggests that the compressor model and the loss correlations can be used to simulate the performance of different machine geometries and working fluids with sufficient accuracy.

In order to show the relevance for a practical application, the proposed design method was applied to the case study of a top cycle of a high-temperature heat pump supplying steam at $150{ }^{\circ} \mathrm{C}$. To this end, the compressor design model was coupled to the cycle design model, and a multi-objective optimization was performed. The decision variables of the compressor design model were optimized to maximize the cycle coefficient of performance and the supply heat flow rate. The method was applied to two different configurations: a closed-loop cycle using a selected refrigerant, and an open-loop using a two-stage compressor with water, which is representative of the current benchmark for such high-temperature heat pumps. In the closed-loop cycle, five working fluids were selected and analyzed.

Compared to a simple estimate of compressor efficiency and volume flow rate, the optimization of the integrated cycle and validated compressor models allowed finding more accurate results and restricting the solution space to more feasible designs also considering the compressor design criteria.

The open-loop with the two-stage water compressor achieves the highest values of coefficient of performance and heat flow rate, respectively, 5.48 and 1734 $\mathrm{kW}$. At the same time, the design of a suitable water vapor compressor is found to be more challenging due to the high values of rotational speed, the low values of mass flow rate and the large pressure ratio, which in turn require the adoption of a two-stage solution. Moreover, the high values of rotational speed resulted in higher losses in the impeller and diffuser which will require special care in the fluid-dynamics design of the machine. A closed-loop with cyclopentane is indicated to be the second best option in terms of the coefficient of performance. In this case, the heat pump cycle would feature a lower coefficient of performance of 4.74 in favor of a simpler compressor design: a single-stage configuration with a backward swept impeller and lower rotational speed.

\section{Acknowledgements}

The research work was conducted within the frame of the THERMCYC project ("Advanced thermodynamic cycles utilizing low-temperature heat sources"; project ID: 1305-00036B, see http://www.thermcyc.mek.dtu. dk/) funded by Innovation Fund Denmark, The Danish Council for Strategic Research in Sustainable Energy and Environment.

\section{References}

[1] S. Wolf, M. Blsels, Model-based quantification of the contribution of industrial heat pumps to the European climate change mitigation strategy, in: Proceedings of the ECEEE Industrial Efficiency Conference 2016, September 12-14, Kalkscheune, Berlin, Germany, 2016, pp. 477-487.

[2] C. Arpagaus, F. Bless, J. Schiffmann, S. S. Bertsch, Multitemperature heat pumps: A literature review, International Journal of Refrigeration 69 (2016) 437-465.

[3] C. Arpagaus, F. Bless, M. Uhlmann, J. Schiffmann, S. S. Bertsch, High temperature heat pumps: Market overview, state of the art, research status, refrigerants, and application potentials (2018).

[4] K. J. Chua, S. K. Chou, W. M. Yang, Advances in heat pump systems: A review (2010). doi : 10.1016/j . apenergy . 2010.06 .014

[5] IEA, Application of Industrial Heat Pumps, Final report, Part 1. Report No. HPP-AN35-1, Tech. rep. (2014)

[6] P. Nellissen, S. Wolf, Heat pumps in non-domestic applications in Europe: potential for an energy revolution, in: 8th EHPA European Heat Pump Forum, May 28, Brussels, Belgium, 2015, pp. $1-17$

[7] A. S. Wallerand, M. Kermani, I. Kantor, F. Maréchal, Optimal heat pump integration in industrial processes, Applied Energy 219 (2018) 68-92.

[8] J. Zhang, H.-H. Zhang, Y.-L. He, W.-Q. Tao, A comprehensive review on advances and applications of industrial heat pumps based on the practices in China, Applied Energy 178 (2016) $800-825$.

[9] J. K. Jensen, Industrial heat pumps for high temperature process applications: A numerical study of the ammonia-water hybrid absorption-compression heat pump, Ph.D. thesis, Technical University of Denmark (DTU), Lyngby, Denmark (2016). 
[10] O. Bamigbetan, T. M. Eikevik, P. Nekså, M. Bantle, Review of vapour compression heat pumps for high temperature heating using natural working fluids, International Journal of Refrigeration 80 (2017) 197-211

[11] J. Schiffmann, D. Favrat, Design, experimental investigation and multi-objective optimization of a small-scale radial compressor for heat pump applications, Energy 35 (1) (2009) 436450.

[12] J. Schiffmann, Integrated Design and Multi-objective Optimization of a Single Stage Heat-Pump Turbocompressor, Journal of Turbomachinery 137 (7) (2015) 071002.

[13] M. Hastbacka, J. Dieckmann, A. Bouza, Small High Speed: Centrifugal Compressors, ASHRAE Journal 55 (2) (2013) 6364.

[14] J. Süß, A centrifugal compressor cooling system using water as working fluid, in: 12th IIR Gustav Lorentzen Conference on Natural Refrigerants (GL2016), August 21-24, Edimburgh, UK, 2016, pp. 1-7.

[15] S. Bertsch, C. Arpagaus, F. Bless, A. Weickgenannt, J. Schiffmann, Theoretical Investigation of a High Temperature Heat Pump using a Micro Turbo Compressor and Water as a Refrigerant, in: 13th IIR Gustav Lorentzen Conference, June 18-20, Valencia, Spain, 2018, pp. 1-9.

[16] P. Y. Li, C. W. Gu, Y. Song, A new optimization method for centrifugal compressors based on 1D calculations and analyses, Energies 8 (5) (2015) 4317-4334.

[17] E. Klausner, U. Gampe, Evaluation and Enhancement of a One-Dimensional Performance Analysis Method for Centrifugal Compressors, in: Proceedings of the Asme Turbo Expo: Turbine Technical Conference and Exposition, June 16-20, ASME, Düsseldorf, Germany, 2014, p. V02DT42A005.

[18] B. Kus, P. Nekså, Development of one-dimensional model for initial design and evaluation of oil-free $\mathrm{CO} 2$ turbo-compressor, International Journal of Refrigeration 36 (8) (2013) 2079-2090.

[19] P. Harley, S. Spence, D. Filsinger, M. Dietrich, J. Early, An Evaluation of 1D Design Methods for the Off-Design Performance Prediction of Automotive Turbocharger Compressors, in: ASME Turbo Expo 2012: Turbine Technical Conference and Exposition, June 11-15, Copenhagen, Denmark, 2012, pp. 111.

[20] M. Casey, C. Robinson, A Method to Estimate the Performance Map of a Centrifugal Compressor Stage, Journal of Turbomachinery 135 (2) (2012) 021034

[21] R. B. Vilim, A one-dimensional compressor model for supercritical carbon dioxide applications, in: 2010 International Conference on Advances in Nuclear Power Plants (ICAPP'10), June 13-17, San Diego, CA, USA, 2010, pp. 1-12.

[22] J. Veres, Axial and Centrifugal Compressor Mean Line Flow Analysis Method, in: 47th AIAA Aerospace Sciences Meeting including The New Horizons Forum and Aerospace Exposition, January 5-8, American Institute of Aeronautics and Astronautics, Orlando, Florida, USA, 2009, pp. 1-38.

[23] H. W. Oh, E. S. Yoon, M. K. Chung, An optimum set of loss models for performance prediction of centrifugal compressors, Proceedings of the Institution of Mechanical Engineers, Part A: Journal of Power and Energy 211 (4) (1997) 331-338.

[24] R. H. Aungier, Mean Streamline Aerodynamic Performance Analysis of Centrifugal Compressors, Journal of Turbomachinery 117 (3) (1995) 360

[25] A. Perdichizzi, M. Savini, Aerodynamic and geometric optimization for the design of centrifugal compressors, International Journal of Heat and Fluid Flow 6 (1) (1985) 49-56.

[26] M. Galvas, Fortran program for predicting off-design performance of centrifugal compressors, Tech. rep. (1973).

[27] C. Rodgers, Typical Performance Characteristics of Gas Turbine
Radial Compressors, Journal of Engineering for Power 86 (2) (1964) 161

[28] C. Rodgers, A Diffusion Factor Correlation for Centrifugal Impeller Stalling, Journal of Engineering for Power 100 (4) (1978) 592.

[29] C. Rodgers, Efficiency of centrifugal compressor impellers, in: AGARD 282 conference proceedings, May 7-9, Brussels, Belgium, 1980, pp. 1-14.

[30] C. Rodgers, Static pressure recovery characteristics of some radial vaneless diffusers, Canadian Aeronautics and Space Journal 30 (1984) 42-54

[31] J. Coppage, F. Dallenbach, Study of supersonic radial compressors for refrigeration and pressurization systems, Tech. rep., Garret Corp. (1956).

[32] M. Chamoun, R. Rulliere, P. Haberschill, J. Berail, Water vapour as refrigerant for a new high temperature heat pump, in: 23rd IIR International Congress of Refrigeration, August 21-26, Prague, Czech Republic, 2011, pp. 1-8.

[33] P. De Larminat, D. Arnon, Natural or synthetic refrigerants what options for high temperature heat pumps?, in: 10th IIR Gustav Lorentzen Conference on Natural Refrigerants, June 2527, Delft, The Netherlands, 2012, pp. 1-8.

[34] P. A. Domanski, J. Steven Brown, J. Heo, J. Wojtusiak, M. O. McLinden, A thermodynamic analysis of refrigerants: Performance limits of the vapor compression cycle, International Journal of Refrigeration 38 (1) (2014) 71-79.

[35] M. O. McLinden, A. F. Kazakov, J. Steven Brown, P. A. Domanski, A thermodynamic analysis of refrigerants: Possibilities and tradeoffs for Low-GWP refrigerants, International Journal of Refrigeration 38 (1) (2014) 80-92.

[36] C. Kondou, S. Koyama, Thermodynamic assessment of hightemperature heat pumps using low-GWP HFO refrigerants for heat recovery, International Journal of Refrigeration 53 (2015) 126-141.

[37] O. Bamigbetan, T. M. Eikevik, P. Nekså, M. Bantle, Evaluation of Natural working fluids for the Development of high temperature heat pumps, in: 12th IIR Gustav Lorentzen Conference on Natural Refrigerants GL2016, August 21-24, Edimburgh, UK, 2016, pp. 1-8.

[38] L. Da Lio, G. Manente, A. Lazzaretto, Predicting the optimum design of single stage axial expanders in ORC systems: Is there a single efficiency map for different working fluids?, Applied Energy 167 (2016) 44-58.

[39] M. White, A. I. Sayma, Improving the economy-of-scale of small organic rankine cycle systems through appropriate working fluid selection, Applied Energy 183 (2016) 1227-1239.

[40] A. Meroni, J. G. Andreasen, G. Persico, F. Haglind, Optimization of organic Rankine cycle power systems considering multistage axial turbine design, Applied Energy 209 (2018) 339-354.

[41] A. Meroni, A. La Seta, J. G. Andreasen, L. Pierobon, G. Persico, F. Haglind, Combined Turbine and Cycle Optimization for Organic Rankine Cycle Power Systems - Part A: Turbine Model, Energies 9 (5) (2016) 313, 1-15.

[42] A. La Seta, A. Meroni, J. G. Andreasen, L. Pierobon, G. Persico, F. Haglind, Combined Turbine and Cycle Optimization for Organic Rankine Cycle Power Systems - Part B: Application on a Case Study, Energies 9 (6) (2016) 393, 1-17.

[43] A. Javed, C. Arpagaus, S. Bertsch, J. Schiffmann, Smallscale turbocompressors for wide-range operation with large tipclearances for a two-stage heat pump concept, International Journal of Refrigeration 69 (2016) 285-302.

[44] The Mathworks Inc., MATLAB - MathWorks (2016). URL http://www.mathworks.com/products/matlab/

[45] I. H. Bell, J. Wronski, S. Quoilin, V. Lemort, Pure and pseudopure fluid thermophysical property evaluation and the open- 
source thermophysical property library coolprop, Industrial and Engineering Chemistry Research 53 (6) (2014) 2498-2508.

[46] E. W. Lemmon, M. L. Huber, M. O. McLinden, NIST reference fluid thermodynamic and transport properties-REFPROP (2002).

[47] S. L. Dixon, C. A. Hall, Fluid Mechanics and Thermodynamics of Turbomachinery, seventh Edition, Butterworth-Heinemann, Oxford, UK, 2014.

[48] D. Japikse, Centrifugal compressor design and performance, Concepts ETI Inc., Wilder, VT, USA, 1996.

[49] C. Xu, R. S. Amano, Empirical design considerations for industrial centrifugal compressors, International Journal of Rotating Machinery 2012 (2012) 1-15.

[50] D. Japikse, N. Baines, Introduction to turbomachinery, Concepts ETI, Norwich, VT, USA, 1994.

[51] A. Whitfield, N. C. Baines, Design of radial turbomachines, John Wiley and Sons Inc., New York, NY, USA, 1990.

[52] J. D. Stanitz, One-dimensional compressible flow in vaneless diffusers of radial-and mixed-flow centrifugal compressors, including effects of friction, heat transfer and area change, Tech. rep., NASA (1952).

[53] D. Japikse, Advanced diffusion levels in turbocharger compressors and component matching, in: 1st International Conference on Turbocharging and Turbochargers, April 26-28, London, UK, 1982, pp. 143-155.

[54] R. H. Aungier, Centrifugal compressors: a strategy for aerodynamic design and analysis, ASME Press, New York, NY, USA, 2000 .

[55] B. W. Botha, A. Moolman, Determining the impact of the different losses on centrifugal compressor design, R\&D journal 21 (3) (2005) 1-9.

[56] F. J. Wiesner, A Review of Slip Factors for Centrifugal Impellers, Journal of Engineering for Gas Turbines and Power 89 (4) (1967) 558-566.

[57] D. Japikse, A Critical Evaluation of Three Centrifugal Compressors With Pedigree Data Sets: Part 5Studies in Component Performance, Journal of Turbomachinery 109 (1) (1987) 1.

[58] D. Eckardt, Instantaneous Measurements in the Jet-Wake Discharge Flow of a Centrifugal Compressor Impeller, Journal of Engineering for Power 97 (3) (1975) 337.

[59] D. Eckardt, K. Trültzsch, W. Weimann, Vergleichende Strömungsuntersuchungen an drei Radialverdichter-Laufrädern mit konventionellen Meßverfahren, Ph.D. thesis (1977).

[60] D. Eckardt, Flow field analysis of radial and backswept centrifugal compressor impellers. I-Flow measurements using a laser velocimeter, in: Proceedings of the Twenty-fifth Annual International Gas Turbine Conference and Exhibit and Twenty-second Annual Fluids Engineering Conference, March 9-13, New Orleans, Louisiana, USA, 1980, pp. 77-86.

[61] J. Schiffmann, D. Favrat, Theoretical design of a high-speed low power radial turbocompressor, in: 6th European Turbomachinery Conference, 7-11 March, Lille, France, 2005, pp. 1-11.

[62] J. Schiffmann, D. Favrat, High-Speed Low Power Radial Turbocompressor For Oil-Free Heatpumps, in: International Compressor Engineering Conference at Purdue, July 17-20, 2006, pp. $1-8$.

[63] J. Demierre, A. Rubino, J. Schiffmann, Modeling and Experimental Investigation of an Oil-Free Microcompressor-Turbine Unit for an Organic Rankine Cycle Driven Heat Pump, Journal of Engineering for Gas Turbines and Power 137 (3) (2015) 1-10.

[64] S. A. Wright, R. F. Radel, M. E. Vernon, G. E. Rochau, P. S. Pickard, Operation and Analysis of a Supercritical CO2 Brayton Cycle, Tech. rep. (2010).

[65] R. Pecnik, E. Rinaldi, P. Colonna, Computational Fluid Dynamics of a Radial Compressor Operating With Supercritical CO2,
Journal of Engineering for Gas Turbines and Power 134 (12) (2012) 122301

[66] E. Rinaldi, R. Pecnik, P. Colonna, Computational Fluid Dynamic Simulation of a Supercritical CO2 Compressor Performance Map, Journal of Engineering for Gas Turbines and Power 137 (7) (2015) 072602.

[67] V. N. Šarevski, M. N. Šarevski, Energy efficiency of the thermocompression refrigerating and heat pump systems, in: International Journal of Refrigeration, Vol. 35, 2012, pp. 1067-1079.

[68] P. Colonna, N. R. Nannan, A. Guardone, E. W. Lemmon, Multiparameter equations of state for selected siloxanes, Fluid Phase Equilibria 244 (2) (2006) 193-211.

[69] H. Madsbøll, M. Weel, A. Kolstrup, Development of a water vapor compressor for high temperature heat pump applications, in: 24th IIR International Congress of Refrigeration, August 1622, Yokohama, Japan, 2015, pp. 1-8.

[70] W. Jansen, A method for calculating the flow in a centrifugal impeller when entropy gradients are present, in: Royal Society conference on internal aerodynamics (turbomachinery), 19-21 July, Cambridge, UK, 1967, pp. 133-146.

[71] J. P. Johnston, R. C. Dean, Losses in Vaneless Diffusers of Centrifugal Compressors and Pumps: Analysis, Experiment, and Design, Journal of Engineering for Power 88 (1) (1966) 49.

[72] J. W. Daily, R. E. Nece, Chamber Dimension Effects on Induced Flow and Frictional Resistance of Enclosed Rotating Disks, Journal of Basic Engineering 82 (1) (1960) 217-230.

[73] O. Conrad, K. Raif, M. W. Of, The calculation of performance maps for centrifugal compressors with vane-island diffusers, in: Proceedings of the Twenty-fifth Annual International Gas Turbine Conference and Exhibit and Twenty-second Annual Fluids Engineering Conference, March 9-13, American Society of Mechanical Engineers, New Orleans, Louisiana, USA, 1980, pp. 135-147.

[74] D. Eckardt, Detailed Flow Investigations Within a High-Speed Centrifugal Compressor Impeller, Journal of Fluids Engineering 98 (3) (1976) 390.

[75] J. Schiffmann, D. Favrat, Experimental investigation of a direct driven radial compressor for domestic heat pumps, International Journal of Refrigeration 32 (8) (2009) 1918-1928.

[76] J. Schiffmann, Small-scale and oil-free turbocompressor for refrigeration applications, in: 22nd International Compressor Engineering Conference at Purdue, 14-17 July, West Lafayette, Indiana, USA, 2014, pp. 1-11.

[77] B. Monge, Design of supercritical carbon dioxide centrifugal compressors, Ph.D. thesis, University of Seville, Seville, Spain (2014).

[78] M. N. Šarevski, V. N. Šarevski, Characteristics of water vapor turbocompressors applied in refrigeration and heat pump systems, International Journal of Refrigeration 35 (5) (2012) 14841496.

[79] M. Bantle, Turbo-compressors: Prototype tests of mechanical vapour re-compression for steam driers, in: 12th IEA Heat Pump Conference, June, Rotterdam, The Netherlands, 2017.

[80] M. Bantle, Steam compression and the development of a cost effective turbo compressor, in: B. Elmegaard, B. Zühlsdorf, L. Reinholdt, M. Bantle (Eds.), Book of presentations of the International Workshop on High Temperature Heat Pumps., Kgs. Lyngby: Technical University of Denmark (DTU), 2017, pp. 137-141. 


\section{Nomenclature}

\begin{tabular}{|c|c|c|c|c|c|}
\hline \multicolumn{3}{|l|}{ Symbols } & $\rho$ & Density & $\mathrm{kg} / \mathrm{m}^{3}$ \\
\hline$A$ & Cross-sectional area & $\mathrm{m}^{2}$ & $\varepsilon$ & Clearance gap & $\mathrm{m}$ \\
\hline AR & Vaned diffuser area ratio & - & $\varepsilon_{\mathrm{w}}$ & Wake fraction at impeller exit & - \\
\hline AS & Vaned diffuser aspect ratio & - & $\eta$ & Compressor isentropic efficiency & - \\
\hline$b$ & Blade width & $\mathrm{m}$ & $\sigma$ & Impeller slip factor & - \\
\hline$C$ & Absolute velocity & $\mathrm{m} / \mathrm{s}$ & $\phi$ & Flow coefficient & - \\
\hline$C_{f}$ & Diffuser friction factor & - & $\chi$ & Secondary flow mass fraction & - \\
\hline $\mathrm{COP}$ & Coefficient of performance & - & $\psi$ & Stage loading coefficient & - \\
\hline \multirow[t]{2}{*}{$\mathrm{CP}$} & Diffuser pressure recovery & - & \multicolumn{3}{|c|}{ Subscripts } \\
\hline & coefficient & & 0 & total, impeller inlet & \\
\hline$d_{\mathrm{hb}}$ & Hydraulic diameter & $\mathrm{m}$ & 1 & impeller throat static conditions & \\
\hline$D_{f}$ & Blade diffusion factor & - & 01 & impeller throat total conditions & \\
\hline DR & Degree of reaction & - & 2 & impeller exit static conditions & \\
\hline$\dot{m}$ & Mass flow rate & - & 02 & impeller exit total conditions & \\
\hline$h$ & Specific enthalpy & $\mathrm{J} / \mathrm{kg}$ & 3 & diffuser inlet static conditions & \\
\hline$k_{\mathrm{s}}$ & Blade surface roughness & $\mathrm{m}$ & 03 & diffuser inlet total conditions & \\
\hline$K$ & $\begin{array}{l}\text { Total pressure loss coeffi- } \\
\text { cient }\end{array}$ & - & $\begin{array}{l}4 \\
04\end{array}$ & $\begin{array}{l}\text { diffuser throat static conditions } \\
\text { diffuser throat total conditions }\end{array}$ & \\
\hline$L_{\mathrm{z}}$ & Rotor axial length & $\mathrm{m}$ & 5 & diffuser exit static conditions & \\
\hline$L_{\mathrm{b}}$ & Blade hydraulic length & $\mathrm{m}$ & 05 & diffuser exit total conditions & \\
\hline LWR & $\begin{array}{l}\text { Vaned diffuser length over } \\
\text { width }\end{array}$ & - & $\begin{array}{l}\mathrm{a} \\
\mathrm{b}, \mathrm{b}\end{array}$ & $\begin{array}{l}\text { axial direction } \\
\text { blade, back face }\end{array}$ & \\
\hline$M$ & Mach number & - & $\mathrm{ch}$ & choking & \\
\hline$N$ & Rotational speed & $\mathrm{rpm}$ & $\mathrm{cl}$ & clearance & \\
\hline$o$ & Throat & $\mathrm{m}$ & $\mathrm{h}$ & hub & \\
\hline$p$ & Static pressure & $\mathrm{Pa}$ & vs & interspace & \\
\hline PR & Pressure ratio & - & $\mathrm{vd}$ & vaned diffuser & \\
\hline$\dot{Q}$ & Heat flow rate & $\mathrm{W}$ & $\mathrm{tt}$ & total-to-total & \\
\hline$r$ & Radius & $\mathrm{m}$ & ts & total-to-static & \\
\hline$R e$ & Reynolds number & - & th & throat & \\
\hline$s$ & Specific entropy & $\mathrm{J} /(\mathrm{kgK})$ & $\mathrm{t}$ & trailing edge, tangential direction & \\
\hline$t$ & Trailing edge thickness & $\mathrm{m}$ & sf & skin friction & \\
\hline$T$ & Temperature & $\mathrm{K}$ & $\mathrm{s}$ & shroud & \\
\hline$U$ & Peripheral velocity & $\mathrm{m} / \mathrm{s}$ & $\mathrm{rms}$ & root-mean-square & \\
\hline$\dot{V}_{\text {comp,in }}$ & $\begin{array}{l}\text { Compressor inlet volume } \\
\text { flow rate }\end{array}$ & $\mathrm{m}^{3} / \mathrm{s}$ & $\begin{array}{l}\text { rel } \\
\text { rc }\end{array}$ & $\begin{array}{l}\text { relative } \\
\text { recirculation }\end{array}$ & \\
\hline$W$ & Relative velocity & $\mathrm{m} / \mathrm{s}$ & $\mathrm{r}$ & radial direction, rotor & \\
\hline$Z$ & Number of blades & - & $\mathrm{pp}$ & pinch point & \\
\hline \multicolumn{3}{|c|}{ Abbreviation and acronyms } & opt & optimal & \\
\hline $\mathrm{CC}$ & & $\operatorname{mix}$ & mixing & \\
\hline HP & & & $\mathrm{m}$ & meridional direction & \\
\hline HTHP & \multicolumn{2}{|l|}{ High-Temperature Heat Pump } & $\lim$ & limit value & \\
\hline VD & Vaned Diffuser & & $\begin{array}{l}\text { is } \\
\text { ind }\end{array}$ & isentropic & \\
\hline \multicolumn{3}{|c|}{ Greek letters } & & $\begin{array}{l}\text { Inaucer } \\
\text { incidence }\end{array}$ & \\
\hline$\alpha$ & Absolute flow angle & $\circ$ & imp & impeller & \\
\hline$\beta$ & Relative flow angle & $\circ$ & id & ideal & \\
\hline
\end{tabular}

